\title{
Arqueoentomología y arqueobotánica de los espacios de almacenamiento a largo plazo: el granero de Risco Pintado, Temisas (Gran Canaria)*
}

\author{
Archaeoentomology and archaeobotany of long-term storage spaces: the granary of Risco \\ Pintado, Temisas (Gran Canaria)
}

\section{Pedro Henríquez-Validoa, Jacob Morales ${ }^{a}$, Paloma Vidal-Matutano ${ }^{\mathrm{b}, \mathrm{c}}$, Jonathan Santana-Cabrera ${ }^{d}$ y Amelia Rodríguez Rodríguez ${ }^{\mathrm{a}}$}

\section{RESUMEN}

Este trabajo pretende contribuir al estudio de las técnicas de almacenamiento utilizadas en el pasado mediante el análisis de los restos entomológicos y vegetales presentes en el granero prehispánico canario de Risco Pintado, fechado entre los siglos IX y $\mathrm{XV}$ cal DC. Este tipo de granero se caracteriza por agrupar numerosos silos excavados en la toba volcánica y situarse en lugares escarpados de difícil acceso y fácil defensa. Las excepcionales condiciones ambientales de estas infraestructuras han permitido la conservación en el interior de los silos de restos desecados de los productos vegetales almacenados y de las plagas asociadas al ensilado. Las especies domésticas documentadas incluyen cereales (cebada y trigo), legumbres (habas y lentejas) y frutales cosechados (higos), así como otros vegetales silvestres recolectados. Junto a estos restos se registran insectos que se desarrollan como plagas primarias y secundarias del almacenamiento (gorgojos del grano y dientes de sierra). Estas plagas se combatieron mediante insecticidas naturales como el laurel y el lentisco. Se analiza la presencia de estas plagas como un indicador de almacenamiento a largo plazo y de las estrategias desarrolladas para asegurar la integridad de los recursos vegetales almacenados.

\begin{abstract}
This contribution aims at understanding the storage techniques used in the past by means of studying the
\end{abstract}

entomological and plant remains present in the pre-hispanic granary of Risco Pintado, dated between the IX and $X V$ centuries cal AD. This type of granary groups together a large number of silos excavated in the volcanic tuff, situated on steep escarpments, difficult to access and easy to defend. The exceptional environmental conditions of these infrastructures have allowed the desiccated remains of the stored plant products and the pests associated with such storage to be preserved within the silos. The domestic species documented include cereals (barley and wheat), legumes (broad beans and lentils) and fruits (figs), as well as other gathered indigenous plants. Together with these remains, insects that developed as primary and secondary storage pests are recorded (grain weevil and sawtoothed grain beetle). To combat these infestations, the ancient Canarians used a number of natural insecticides (laurel and lentisk). The presence of these pests is analysed as an indicator of long-term storage and of the strategies developed to ensure the integrity of stored plant resources.

Palabras clave: Islas Canarias; Prehispánico; Graneros en cuevas; Restos vegetales; Alimentos; Plagas de insectos; Insecticidas.

Key words: Canary Islands; Prehispanic; Granaries in cave; Plant remains; Food; Insects pests; Insecticide.

* Este estudio se enmarca en el proyecto de investigación HAR2017-83205P financiado por el Ministerio de Economía y Competitividad de España. Jacob Morales es beneficiario de un contrato perteneciente al Programa Ramón y Cajal (RYC 2015-18072). Paloma Vidal-Matutano es beneficiaria de un contrato postdoctoral APOSTD (APOSTD/2017/126, Generalitat Valenciana). Pedro Henríquez es beneficiario de un contrato predoctoral de la Universidad de Las Palmas de Gran Canaria (Convocatoria 2017).

${ }^{a}$ G. I. Tarha, Dpto. Ciencias Históricas, Universidad de Las Palmas de Gran Canaria. C/ Pérez del Toro 1. 35003 Las Palmas de Gran Canaria. Islas Canarias. España. Correo e.: pedro.henriquez102@alu.ulpgc.es https://orcid.org/0000-0001-8149-3289; JM https://orcid.org/0000-0002-6781-2121; ARR https://orcid.org/0000-0001-7112-2441.

${ }^{b}$ Grupo de Investigación Prehistoria del Mediterráneo Occidental (G. I. PREMEDOC), Dept. de Prehistòria, Arqueologia i Història Antiga. Universitat de València. C/ Blasco Ibáñez 28. 46010 València. España. https://orcid.org/0000-0002-5892-149X.

c Université Côte-d'Azur - Cultures et Environnement, Préhistoire, Antiquité, Moyen Âge (CEPAM), CNRS. Pôle universitaire Saint-Jean-d'Angély 3. 24 avenue des Diables Bleus. 06357 Nice Cedex 4. Francia.

${ }^{d}$ Marie Curie Fellow. Dept. of Archaeology. Durham University. South Road. Durham. DH1 3LE. Reino Unido. https://orcid.org/0000-0002-9615-8560

Recibido 7-V-2018; aceptado 17-IX-2018. y distribución "Creative Commons Reconocimiento 4.0 Internacional" (CC BY 4.0). 


\section{INTRODUCCIÓN}

El almacenamiento de los alimentos a largo plazo es una actividad fundamental para la supervivencia de muchas sociedades, en especial de poblaciones agrícolas centradas en el cultivo de granos y que dependen de la cosecha almacenada para sortear las fluctuaciones climáticas y de la producción (Winterhalder et al. 2015). A pesar de su importancia, los procesos y técnicas de almacenamiento de sociedades prehistóricas y antiguas no siempre se han abordado en profundidad, ya que la mayor parte de la atención se ha centrado en aspectos de la producción, como la cosecha, el procesado o el consumo (Sigaut 1981). Entre otras razones, la carencia de este tipo de estudios deriva de los problemas de preservación que son intrínsecos a los productos vegetales arqueológicos, así como de las dificultades para identificar las técnicas para preservarlos a largo plazo en los contextos arqueológicos (Peña-Chocarro et al. 2015).

Aunque los espacios de almacenamiento han sido identificados arqueológicamente desde al menos la Prehistoria Reciente (Kuijt y Finlayson 2009), apenas se poseen datos directos sobre sus contenidos y las prácticas orientadas a asegurar la efectividad de estos sistemas a largo plazo. En las pocas ocasiones en que se documenta la naturaleza de los productos almacenados, su preservación se produce por carbonización, con las pérdidas de información que esta forma de conservación conlleva (Van der Veen 2007). Estas carencias son más acusadas en el análisis de las plagas que afectaban a los alimentos que se pretendía acumular para el futuro, en especial de los insectos, que muy raras veces han sido investigados (Buckland 1991; Panagiotakopulu 2001; Huchet 2017).

Algunos yacimientos prehispánicos de Gran Canaria permiten evaluar los procesos de almacenamiento de las sociedades pretéritas, dado que presentan una extraordinaria preservación por desecación de los vegetales allí guardados, así como de las plagas que se relacionan con estas plantas (Morales et al. 2014). Esto es debido a la aridez del entorno y a las condiciones ambientales presentes en el interior de los graneros. Las cuevas, en términos generales, son adecuadas para la preservación de materiales orgánicos debido a su humedad y temperatura constantes a lo largo del año, a la vez que protegen de la acción del sol y otros agentes meteorológicos (Culver y Pipan 2009; Bescherer y Beaudry 2015). Estas particularidades, unidas al clima subtropical seco de las Islas Canarias (Morales Matos 2001), han favorecido la conservación por desecado de los alimentos almacenados en estas cavidades. Asimismo, los silos de los graneros de esta isla rara vez aparecen colmatados con tierra, evitando los procesos de deterioro derivados del contacto con el sedimento y sus particularidades físico-químicas. Otro factor importante que ha contribuido a esa preservación es la cronología reciente de estos yacimientos, pues las fechas radiocarbónicas obtenidas comienzan a ser frecuentes a partir del siglo XI cal DC (Morales et al. 2014). La existencia de estos graneros se ha vinculado a una intensificación de la producción agrícola en la última fase del poblamiento aborigen (siglos XI-XV), sirviendo como referente, además, de las teorías que apoyan una mayor complejidad social durante este periodo (Velasco 1998; Onrubia 2003; Delgado 2009; Morales 2010; Rodríguez Rodríguez et al. 2011-2012; Santana et al. 2012).

Los primeros colonos del archipiélago eran de origen norteafricano (Maca Meyer et al. 2004; Springer 2001; Velasco 2015; Hagenblad et al. 2017; RodríguezValera et al. 2017). Las dataciones radiocarbónicas realizadas sobre materiales de vida corta van centrando el proceso de su colonización y desarrollo del poblamiento desde el inicio de la Era hasta el siglo XV d. C. (Velasco 2015; Arco et al. 2017; Morales et al. 2017). El modo de vida de las poblaciones nativas insulares estuvo condicionado por la ausencia de herramientas de metal y animales domésticos de tiro, entre otras innovaciones tecnológicas (Navarro 1997; Santana et al. 2015). Estas circunstancias no impidieron una agricultura que, especialmente en la isla de Gran Canaria, alcanzó altas cotas de desarrollo como prueban la intensificación en la producción y las estrategias avanzadas para almacenar los productos (Morales 2010; Santana et al. 2012; Rodríguez Rodríguez et al. 2011-2012; Moreno y González 2013).

En esta isla se documentan un número importante de graneros (Fig. 1) (Morales et al. 2014), que consisten en silos excavados en la toba volcánica, agrupados en cámaras y localizados en acantilados y riscos de difícil acceso (Onrubia 2003). Desde el siglo XVIII, han sido objeto de interés, suscitando teorías sobre su posible funcionalidad. A mediados del siglo XX se plantea la posibilidad de que estos yacimientos fueran espacios destinados a guardar alimentos, similares a los graneros comunales o graneros fortificados y los denominados magasins de falaise del norte de África (Marcy 1940; Onrubia 1986, 2003; Delaigue et al. 2011; Rodríguez Rodríguez et al. 2011-2012). La existencia de estos espacios de almacenamiento ha servido para explicar aspectos vinculados a la organización de los procesos productivos, a las estrategias de almacenamiento de los recursos bióticos y a su redistribución entre la población prehispánica de Gran Canaria (Jiménez González 1998; Velasco 1998; Onrubia 2003). Sin embargo, los silos y sus contenidos no han sido objeto de análisis sistemáticos hasta muy recientemente, debido a las dificultades y peligrosidad en el acceso a los mismos. Estos estudios se han centrado en los restos carpológicos (Morales et al. 2014), así como en 


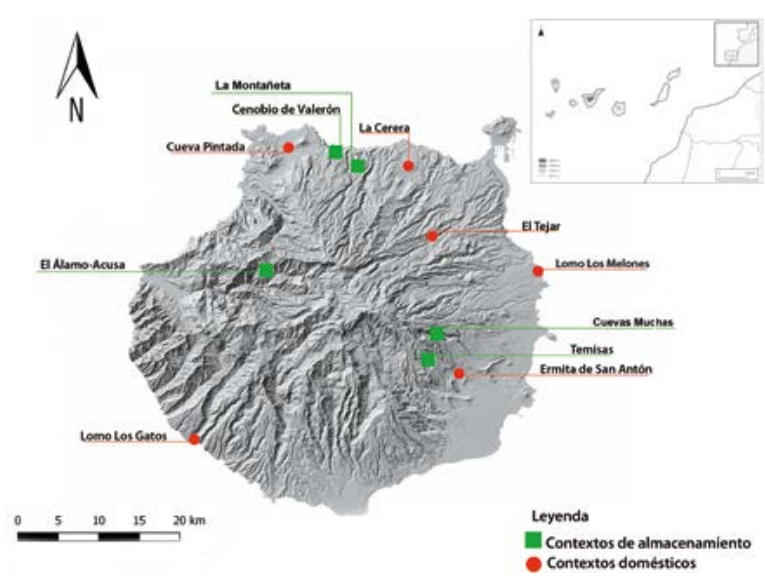

Fig. 1. Localización del archipiélago canario respecto a las costas africanas y la península ibérica y modelo digital de elevaciones de Gran Canaria, extraído a partir del Mapa Topográfico 1:5.000 Año 2011 en https://www.idecanarias.es (consulta 1-10-2017), con la ubicación de los yacimientos citados en este trabajo (en color en la versión electrónica).

las industrias líticas talladas y los materiales de molienda recuperados en uno de los más conocidos, el Cenobio de Valerón (Naranjo y Rodríguez 2015).

Este trabajo se propone: 1) identificar las especies vegetales conservadas, destinadas bien al consumo humano, bien al acondicionamiento del espacio, 2) registrar las plagas presentes en los silos y 3 ) determinar las técnicas de almacenamiento. Es una novedad en España estudiar los métodos de almacenamiento mediante el análisis de las plagas que se asocian a los alimentos acumulados. Se han documentado restos de fauna entomológica en distintos yacimientos de la península ibérica (Moret 1996; Angus y Ribera 1996; Arroyo et al. 2007; Salido 2015), pero no han sido recuperados y analizados de forma sistemática como en este caso.

\section{MATERIAL Y MÉTODO}

\subsection{El granero de Risco Pintado}

El complejo arqueológico al que pertenece este granero, también conocido como La Audiencia, se ubica en el sureste de la isla de Gran Canaria, a $861 \mathrm{~m}$ s. n. m., en la localidad de Temisas (término municipal de Agüimes). Sus coordenadas geográficas son $27^{\circ} 54^{\prime} 25^{\prime \prime} \mathrm{N} ; 1^{\circ} 29^{\prime} 55^{\prime \prime} \mathrm{O}$. Se trata de un conjunto de cuevas artificiales perforadas en un macizo de toba volcánica en la zona denominada como Lomo de la Cruz, en el Barranco de Temisas (Fig. 2). Estas se asocian a usos domésticos, funerarios y de almacena-
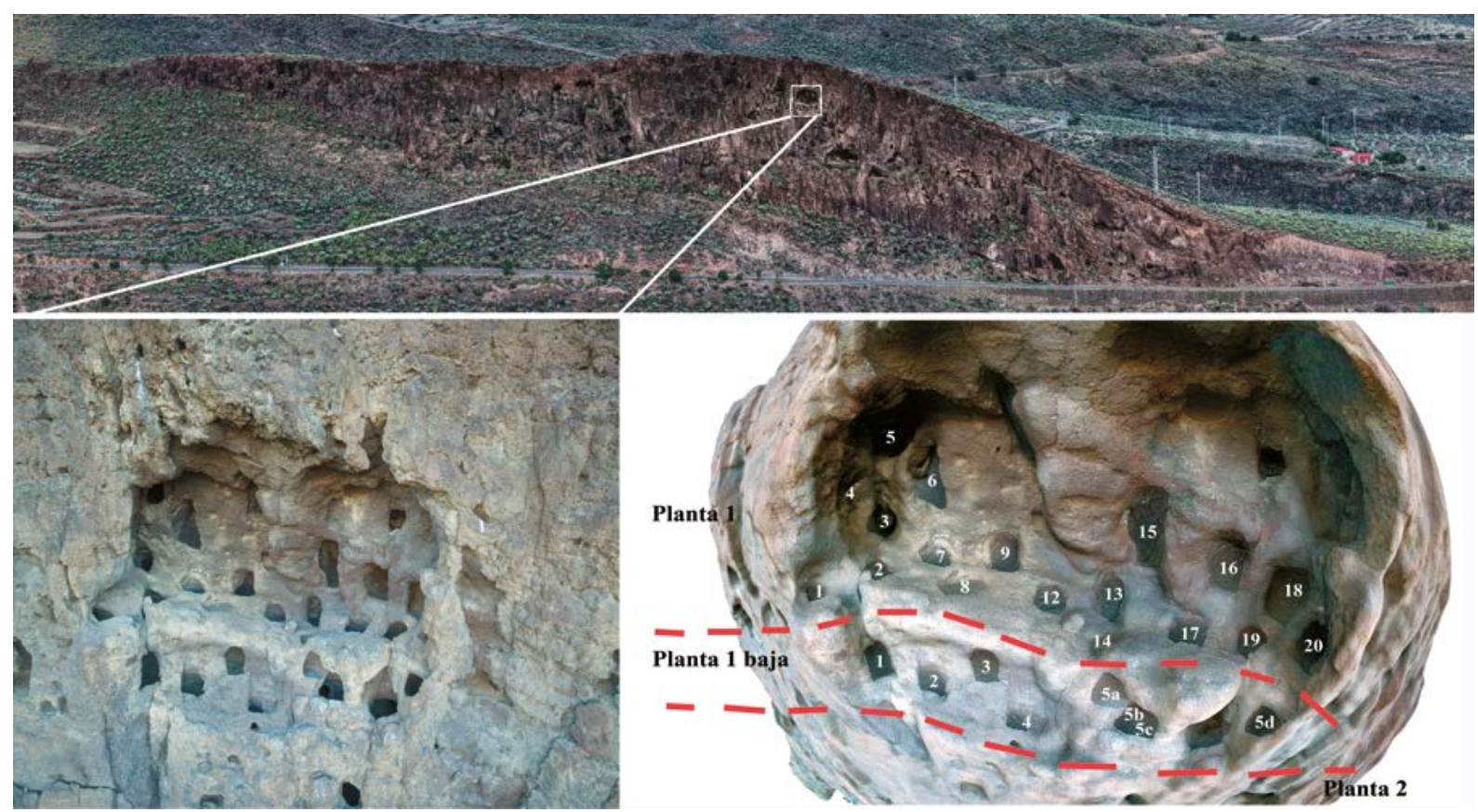

Fig. 2. Complejo arqueológico del Lomo de la Cruz (Temisas, Gran Canaria): A. vista general con el granero de Risco Pintado recuadrado (autor Ernesto Martín). B. Detalle del granero (autor Tibicena Arqueología). C. renderizado del modelo fotogramétrico en Blender con punto de vista panorámico en ojo de pez (autor Ibán Suárez) (en color en la versión electrónica).

Trab. Prehist., 76, N. ${ }^{\circ}$ 1, enero-junio 2019, pp. 120-137, ISSN: 0082-5638

https://doi.org/10.3989/tp.2019.12229 
miento. Una red de caminos y túneles horadados en la roca articula el espacio dentro del conjunto.

El yacimiento aparece citado por primera vez, cuando Sebastián Jiménez Sánchez (1951), el comisario provincial de arqueología durante el franquismo en la provincia de Las Palmas, publicó los resultados de las prospecciones realizadas en Risco Pintado. El comisario describió un conjunto de estructuras de funcionalidad diversa (viviendas, hornos alfareros, un tagoror -que es como se denomina en las fuentes escritas a ciertos espacios de reunión- y cuevas funerarias. En esta intervención, se descubrieron elementos vegetales en junco, recipientes de cerámica y molinos de mano, sin fijarse en los restos menos visibles que aquí analizamos. En 2012, el seguimiento arqueológico durante unas obras en la carretera que pasa frente al yacimiento propició la documentación de nuevas cuevas que contenían maderas, fibras y tejidos vegetales bien preservados, así como molinos de mano, fragmentos de cerámica e industria lítica (Cuenca 2014).

Las muestras que se analizan en este trabajo proceden de un granero, situado en la parte superior central del macizo. Posee 34 silos distribuidos en tres plantas (Fig. 2): 30 silos en la cámara principal, organizados en dos niveles (Planta 1 y Planta 1 Baja) y 4 más en la planta inferior (Planta 2). La disposición de los silos respecto al suelo puede ser horizontal o vertical. Suelen ser cilíndricos o ligeramente troncocónicos, ya que conservan unas dimensiones bastante regulares en toda su planta y alzado (Fig. 3). Con el fin de reconstruir la capacidad máxima de cada cavidad se tomaron medidas del alto y ancho de las bocas, así como de la profundidad máxima de cada silo. Miden unos $96 \mathrm{~cm}$ de altura y $74 \mathrm{~cm}$ de anchura y entre $1 \mathrm{y}$ $4 \mathrm{~m}$ de profundidad (Tab. 1). Estas diferencias en la profundidad se relacionan fundamentalmente con la disposición de las oquedades, ya que las verticales tienen menor desarrollo que las horizontales. Las bocas $\mathrm{y}$ el interior de los silos tienen forma redondeada $u$

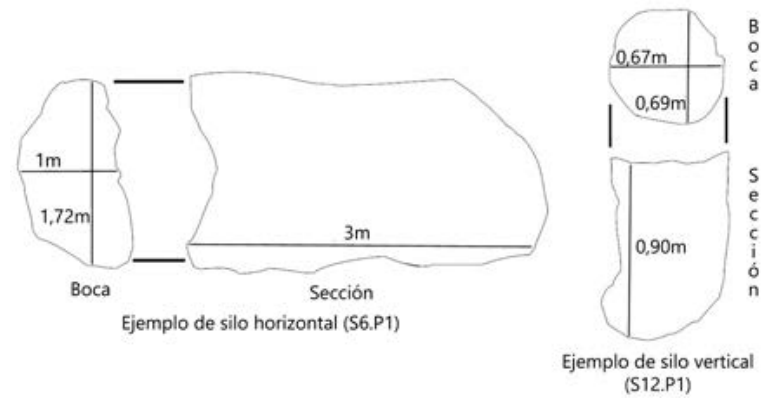

Fig. 3: Dibujo del alzado de las bocas y sección longitudinal de los silos 6 y $12 . P 1$ de Risco Pintado.

\begin{tabular}{|c|c|c|c|c|}
\hline Silo & $\mathbf{X}$ & $\mathbf{Y}$ & $\mathbf{Z}$ & Orientación \\
\hline S1.P1 & 0,67 & 0,68 & 4,38 & Vertical \\
\hline S2.P1 & 0,54 & 0,67 & 2,36 & Vertical \\
\hline S3a.P1 & 0,6 & 1,4 & sin datos & Horizontal \\
\hline S4.P1 & 0,75 & 0,57 & 1,22 & Horizontal \\
\hline S5.P1 & 1,2 & 1,26 & 1,39 & Horizontal \\
\hline S6.P1 & 1 & 1,72 & 3 & Horizontal \\
\hline S7.P1 & 0,72 & 0,67 & 3 & Horizontal \\
\hline S8.P1 & 1 & 0,8 & colmatado & Vertical \\
\hline S9.P1 & 0,82 & 0,92 & 2,5 & Horizontal \\
\hline S10.P1 & 0,8 & 1,22 & 1,2 & Horizontal \\
\hline S11.P1 & 0,83 & 0,96 & 0,8 & Horizontal \\
\hline S12.P1 & 0,67 & 0,69 & 0,9 & Vertical \\
\hline S13.P1 & 0,61 & 1,5 & 3,3 & Horizontal \\
\hline S14.P1 & 0,74 & 0,56 & colmatado & Horizontal \\
\hline S15.P1 & 0,82 & 1,47 & 2,5 & Horizontal \\
\hline S16.P1 & 0,74 & 1,04 & 3,33 & Horizontal \\
\hline S17.P1 & 0,72 & $\sin$ datos & 1,72 & Vertical \\
\hline S18.P1 & 0,68 & 1 & 1,3 & Horizontal \\
\hline S19.P1 & 0,68 & $\sin$ datos & 1,5 & Horizontal \\
\hline S20.P1 & 0,68 & 0,86 & 4,5 & Horizontal \\
\hline S1.P1b & 0,65 & 0,95 & 1,02 & Horizontal \\
\hline S2.P1b & 0,67 & 0,75 & 1,4 & Vertical \\
\hline S3.P1b & 0,6 & 0,85 & 1,4 & Horizontal \\
\hline S4.P1b & 0,6 & 0,6 & 1,3 & Vertical \\
\hline S5a.P1b & $\sin$ datos & $\operatorname{sin~datos~}$ & sin datos & Horizontal \\
\hline S5b.P1b & $\sin$ datos & $\sin$ datos & sin datos & Horizontal \\
\hline S5c.P1b & $\sin$ datos & $\sin$ datos & sin datos & Horizontal \\
\hline S5d.P1b & $\sin$ datos & $\sin$ datos & sin datos & Horizontal \\
\hline & & & & \\
\hline & & & & \\
\hline
\end{tabular}

Tab. 1. Medidas de los silos excavados en Risco Pintado. Están expresadas en metros, salvo que se indique otro valor. $X$ ancho de la boca; Y alto de la boca; $\mathrm{Z}$ profundidad del silo.

ovalada. La situación de este tipo de granero en acantilados de difícil acceso afecta la seguridad en los trabajos propios de una intervención arqueológica, incluyendo los levantamientos topográficos convencionales ${ }^{1}$.

Estas cavidades contienen escasos aportes sedimentarios del exterior, salvo el arrastrado por el viento, y su contenido se compone de una amalgama de restos orgánicos preservados por desecación, entre los que

Un modelo 3D restituido utilizando técnicas fotogramétricas puede ilustrar convenientemente estos aspectos y ser consultado en https://sketchfab.com/models/1256a76c589049b8a916155f6234fb95 


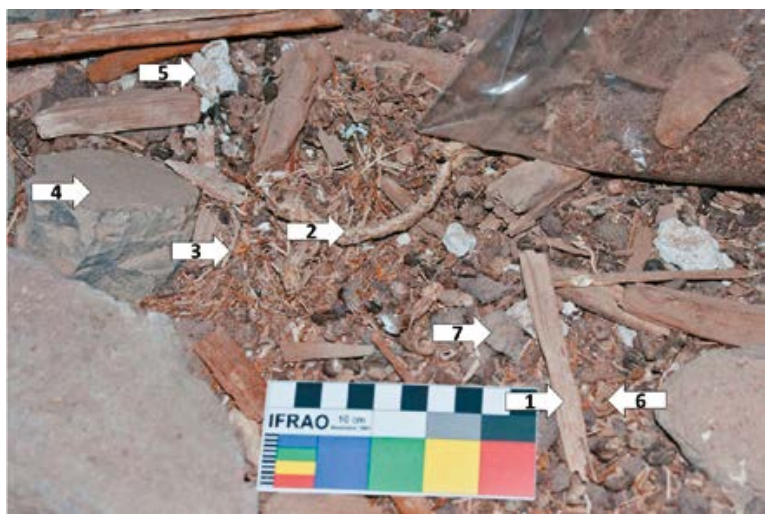

Fig. 4: Detalle de la superficie de un silo de Risco Pintado (Autor: Ernesto Martín, en color en la versión electrónica). Ejemplo de materiales identificados en superficie: 1) madera, 2) fibras y tejidos vegetales, 3) gluma articulada de cereal), 4) industria lítica, 5) fragmentos de argamasas 6) excrementos de animales, 7) roca disgregada.

sobresalen la paja, porciones de cereal y excrementos de animales. También abundan fragmentos de argamasas asociadas a las paredes de los silos o elementos de la propia roca encajante disgregada (Fig. 4).

\subsection{Metodología}

La localización de Risco Pintado en una gran pendiente ha exigido la ayuda de un equipo profesional que asegurara a los participantes de la intervención durante todo el transcurso de la misma. La prospección superficial de los contenidos de los silos mostró un relleno de escasos centímetros de potencia, lo que impedía documentar una secuencia estratigráfica convencional. Asimismo, se advirtió que la excavación completa de estos espacios es inviable por los problemas tanto de seguridad para el acceso y la permanencia en el sitio como de transporte de las herramientas y de los materiales arqueológicos recuperados. Por ello se ha adoptado una estrategia de muestreo que permite obtener evidencias suficientes y comparables entre sí. Consiste en la recogida de 1 litro del sedimento depositado en el interior de cada silo mediante métodos mecánicos sin discriminar ningún material que se hallase en el perímetro seleccionado. La escasa potencia de los depósitos ni permitía advertir microestratigrafías ni aislar tallas artificiales.

Las muestras fueron cribadas en seco utilizando la columna de tamices de $4,2,1$ y $0,5 \mathrm{~mm}$ de luz, habitual en el análisis de macrorrestos vegetales y de insectos. Esta metodología ya ha sido empleada en otros graneros de la isla (Morales et al. 2014), así como en yacimientos de otros lugares del mundo don- de los materiales se conservan por desecación o carbonización (Alonso et al. 2000; Panagiotakopulu et al. $2010,2013)$. No se practicó la flotación con agua (Alonso et al. 2000), ni con parafinas, metodología típica para separar restos de insectos (Coope y Osborne 1968), para no dañar los restos orgánicos y preservarlos para futuros análisis biomoleculares. Además, como estas muestras se caracterizan por su matriz fundamentalmente vegetal, flotaría la mayor parte del contenido.

Las evidencias antracológicas fueron separadas de visu en la fracción superior a $2 \mathrm{~mm}$. Los materiales carpológicos e insectiles fueron separados con la ayuda de una lupa binocular Nikon SMZ-2T de 8-80 X. Las cribas superiores a $2 \mathrm{~mm}$ de cada muestra se estudiaron en su totalidad. Se revisaron respectivamente $1 / 4$ y $1 / 8$ de las fracciones de los tamices de 1 y 0,5 $\mathrm{mm}$ por el elevado número de restos de semillas e insectos. La muestra se fraccionó de modo aleatorio con ayuda de una cuarteadora. La representación de las especies vegetales y de invertebrados fue expresada en valores estimados, multiplicando el número de especímenes identificados en cada fracción y el número total de restos en cada muestra.

Los elementos carpológicos se han identificado comparándolos con los ejemplares presentes en la colección de referencia de semillas modernas, depositada en el Departamento de Ciencias Históricas de la Universidad de Las Palmas de Gran Canaria.

Los restos antracológicos, maderas desecadas y carbones están en proceso de estudio. Para su identificación botánica se ha seguido la metodología antracológica, basada en la observación de los tres planos anatómicos que presenta la madera (transversal, longitudinal tangencial y longitudinal radial) mediante un microscopio óptico de luz transmitida, con objetivos de 50 a 1000 aumentos (Badal y Heinz, 1991; Chabal, 1997). Nos hemos ayudado de bibliografía especializada (Jacquiot 1955; Jacquiot et al. 1973; Schweingruber 1990) y de la colección de referencia de maderas actuales que está creándose en el Centro Instrumental Químico-Físico para el Desarrollo de la Investigación Aplicada de la Universidad de Las Palmas de Gran Canaria (CIDIA) y depositada en el Departamento de Ciencias Históricas de esa universidad.

Para la determinación taxonómica de los restos entomológicos, se ha utilizado información visual y descriptiva presente en la bibliográfica específica (Cranston y Gullan y 2010; Buckland et al. 2014; Huchet 2017). Paralelamente al estudio de los ejemplares arqueológicos, se está creando una colección de referencia de insectos en el citado departamento, que servirá para posteriores análisis arqueoentomológicos en las Islas Canarias y el norte de África. 
Es preciso apuntar que los silos también contienen vestigios de otra naturaleza no estudiados en este trabajo como fragmentos de cerámica, industria lítica tallada, malacofauna y cuerdas y tejidos de fibra vegetal. Una parte de esos repertorios está ya analizándose aunque, en las intervenciones realizadas hasta el momento, el proceso de muestreo empleado implica que su aparición es testimonial.

En cuanto al cálculo de los resultados, el porcentaje de ubicuidad de las especies se halló contabilizando los silos en los que existe presencia del taxón y dividiéndolo por el total (34 silos). Por la fragmentación de los restos, el número mínimo de insectos (NMI) se calculó en cada silo a partir de los pronotos de las distintas especies. Cuando faltaban o el número de cabezas o de abdómenes era superior, se contabilizaron estos últimos elementos. Los números reales de restos de artrópodos se ubican en el Anexo AC1. Se marcan en un rectángulo los restos que, sin ser el tórax, fueron usados para el cálculo del NMI.

\section{RESULTADOS}

El análisis de los silos del granero prehispánico de Risco Pintado ha aportado un número significativo de plantas e insectos. En total, se han contabilizado 10432 restos carpológicos (48 taxones), 112 restos antracológi$\cos$ (6 taxones) y 8951 restos entomológicos (4 taxones).

\subsection{Los restos carpológicos}

Se documentaron nueve taxones que representan el $92 \%$ de los elementos identificados (9715 especímenes) y que se integran en el elenco de las plantas cultivadas y recolectadas por los antiguos habitantes de Gran Canaria (Tab. 2): cebada vestida (Hordeum vulgare subsp. vulgare), trigo duro (Triticum durum), higos (Ficus carica), habas (Vicia faba), lentejas (Lens culinaris), palmera (Phoenix canariensis), laurel (Laurus novocanariensis), lentisco (Pistacia lentiscus) y pino (Pinus canariensis) (Fig. 5). Estas especies han sido documentadas previamente en contextos domésticos prehispánicos (Morales 2010; Morales et al. 2017), así como en el granero de El Álamo-Acusa (Morales et al. 2014).

La cebada es el cereal más abundante dentro del granero. Está presente en el yacimiento con 1277 restos $(14 \%$ del total). Se preserva en tres formas claramente identificables: semillas, glumas articuladas y segmentos de raquis. Las primeras solo tienen 5 individuos registrados. Las glumas articuladas corresponden a la cubierta floral de la semilla que permanece tras el consumo del interior por los insectos; en este

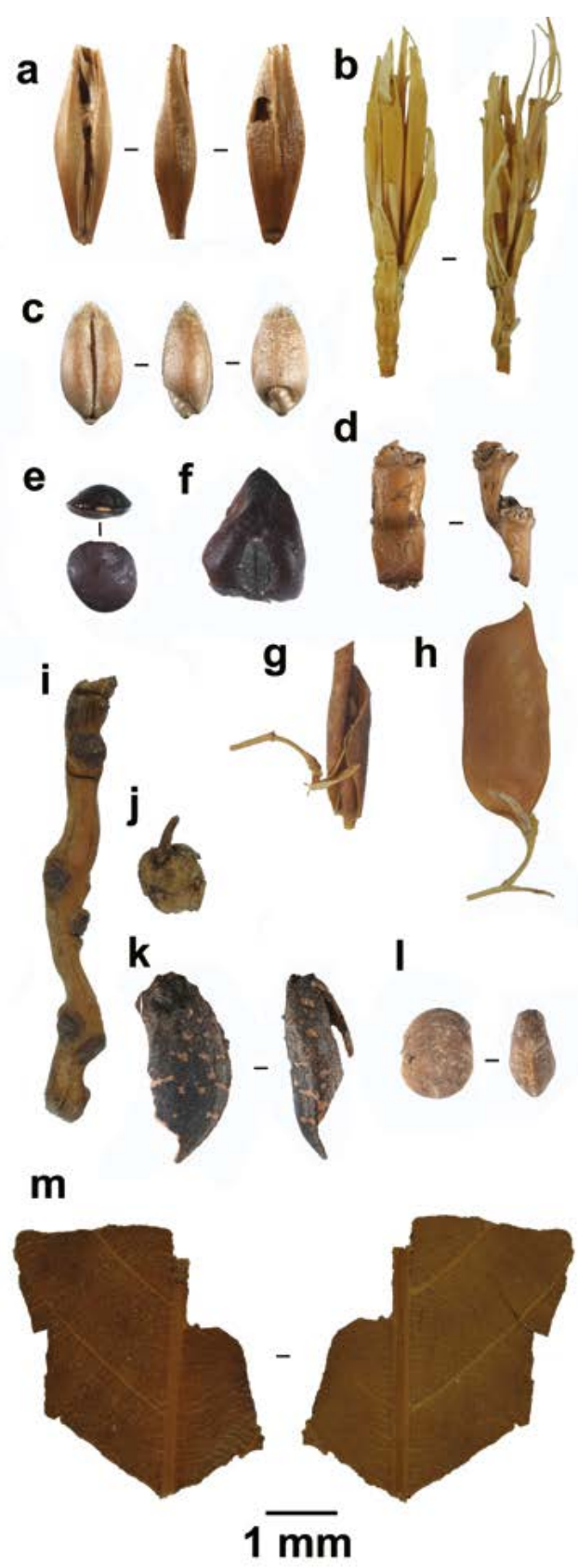

Fig. 5. Restos de plantas recuperadas en Risco Pintado: a. gluma articulada de cebada (Hordeum vulgare); b. raquis de cebada (Hordeum vulgare); c. grano de trigo (Triticum durum); d. raquis de trigo (Triticum durum); e) lenteja (Lens culinaris); f) hilo de haba (Vicia faba) fragmentada; g) vaina de lenteja (Lens culinaris); h) vaina de lenteja actual (procedente de la colección de referencia); i) raquis de támara o dátil (Phoenix canariensis); j) fragmento de támara o dátil (Phoenix canariensis); k) semilla de pino (Pinus canariensis); 1) semilla de lentisco (Pistacia lentiscus); m) fragmento de hoja de laurel (Laurus novocanariensis). Fotos realizadas con una cámara Nikon DS-Fi 1 acoplada a una lupa binocular 8-80 X (en color en la versión electrónica). 


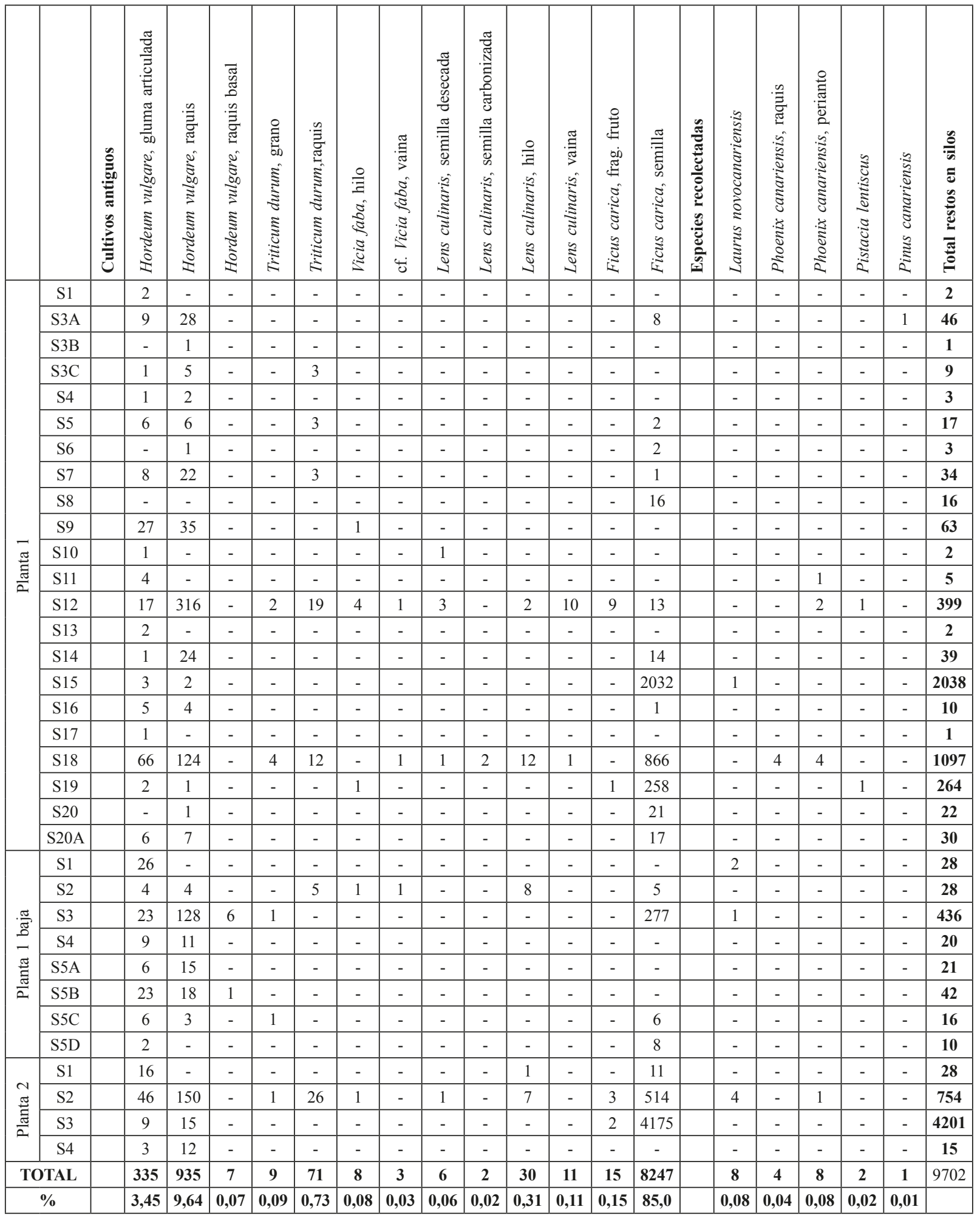

Tab. 2. Número estimado de los restos de plantas explotadas por los antiguos canarios recuperadas en Risco Pintado. $\mathrm{S}=\mathrm{Silo}, \mathrm{P}=\mathrm{Planta}, \mathrm{b}$ $=$ Baja. Volumen de cada muestra $=1$ litro; Volumen total $=34$ litros.

Trab. Prehist., 76, N. ${ }^{\circ}$ 1, enero-junio 2019, pp. 120-137, ISSN: 0082-5638 https://doi.org/10.3989/tp.2019.12229 
caso se han contabilizado 335 elementos. También se han determinado 935 segmentos de raquis, el eje central de la espiga en torno al cual se disponen las semillas. En 7 segmentos el raquis basal y parte del tallo estaban aún articulados. Los segmentos de raquis son la fracción de cebada más numerosa en el registro analizado (73\% de los restos de cebada). Cabe destacar que en todos los muestreados en Risco Pintado se documentaron restos de cebada, salvo en el S8.P1 (porcentaje de ubicuidad de $99 \%$ ).

El trigo duro (Triticum durum) aparece en un porcentaje muy inferior: el $5 \%$ del total de los cereales registrados (80 registros). Supone el 0,69 \% de las semillas identificadas y sólo aparece en 9 de los 34 silos estudiados (ubicuidad de 26,47 \%). Al igual que en el caso de la cebada, los segmentos de raquis vuelven a ser los elementos más abundantes en los silos (88,75\% de todos los elementos de trigo, 71 evidencias). El resto de los elementos son 9 semillas procedentes de 4 silos.

En cuanto a las legumbres, las lentejas (Lens culinaris) con 49 registros, constituyen el 81,66\% de esta familia, repartidas en 6 silos. Se contabilizaron 30 fragmentos del hilo, la cicatriz situada en el punto de unión de la semilla con el fruto; 6 semillas enteras desecadas y 2 semillas carbonizadas. También se registraron 11 fragmentos de vaina, 10 de las cuales proceden del S12.P1.

Las habas (Vicia faba) con 11 registros, repartidos en 4 silos, representan el 18,34\% restante. Se documentaron 8 fragmentos de la testa con el hilo aún adherido y 3 restos de vainas. Destaca el S12.P1 con la mitad de los hilos hallados y 1 vaina fragmentada.

Respecto a los higos (Ficus carica), con 8262 registros alcanzan el $85 \%$ del total de restos vegetales documentados en Risco Pintado. La mayoría son semillas (endocarpos), aunque también hay 15 fragmentos de fruto. El S12.P1 destaca sobre los demás, donde aparecieron 9 fragmentos. Sin embargo, la abundancia de esta especie debe ser interpretada con precaución. La elevada cantidad de semillas que contiene cada fruto, así como su gran dureza, facilita su conservación en los silos. Se hallaron semillas de higos en 20 de los 34 silos analizados.

Junto a estas evidencias de plantas domésticas hemos identificado especies silvestres que pudieron ser objeto de recolección y fueron depositadas en el interior de los silos. Representan un 0,23 \% del total de restos vegetales registrados (41 registros).

Una de las especies más abundantes es el laurel (Laurus novocanariensis), del que se han encontrado 8 fragmentos de hojas en cuatro silos. Las hojas presentan una superficie reticulada en la que se observan unas pequeñas glándulas junto a las nervaduras. Esta especie es un árbol endémico de las islas que aparece con preferencia en la vertiente septentrional, a unos 500 y 1200 m de altitud (Bramwell y Bramwell 2001), y por tanto a una cierta distancia del granero de Risco Pintado (ca. $10 \mathrm{~km}$ ). Además se identificaron algunos fragmentos de madera de Lauraceae, que se detallarán más adelante.

En los silos también encontramos frutos de la palmera canaria (Phoenix canariensis). Esta especie de arecáceas, otro endemismo del archipiélago, se ha identificado a partir de 4 segmentos del raquis (eje central en torno al que se disponen los frutos, dátiles o támaras) y 8 fragmentos del perianto (unión del fruto al racimo). Los restos de palmera proceden de 4 de los 32 silos de Risco Pintado: S11, 12, 18.P1 y S2.P2.

Dos semillas de lentisco (Pistacia lentiscus) se recuperaron en los S.12 y 19. En S3.P1, se registró un fragmento de escala de las piñas del pino canario $(\mathrm{Pi}$ nus canariensis), una conífera endémica de la familia de las pináceas.

Además, se documentaron en el interior de los silos 717 semillas agrupadas en 39 taxones (Anexo AC2), que posiblemente no fueron explotadas por los antiguos canarios, sino que fueron introducidas tras el abandono de los graneros. Es preciso puntualizar que, aunque las bocas de los silos presentan huellas de haber estado selladas con maderas, losas de piedra y argamasas, en la actualidad no están cerrados (sin que sepamos cuando dejaron de estarlo), facilitando el acceso a las distintas especies animales que merodean el granero, y alterando su contenido. Algunas de estas especies coinciden con cultivos llegados a las islas tras la conquista y colonización europea, y otras a la flora silvestre y adventicia presente en torno al yacimiento. La introducción de estas especies vegetales en el interior de los silos responde a la acción de animales (aves, roedores y lagartos), cuyos excrementos se han documentado en gran número; así como a la acción del viento, que transporta hasta los silos las diásporas de distintas especies adaptadas a la dispersión aérea (ej. individuos pertenecientes a la familia de las Asteraceas y las Gramíneas) (Morales et al. 2014).

\subsection{Los restos antracológicos}

El análisis antracológico en el granero de Risco Pintado, todavía en un estadio preliminar, pone de manifiesto la presencia de un conjunto escaso de carbones y una presencia mayor de fragmentos de maderas desecadas. En total, se contabilizaron 112 restos antracológicos agrupados en 6 taxones (Fig. 6).

Respecto a la madera, tan solo un total de 8 carbones han sido recuperados en el S13, identificándose 2 taxones: Pinus canariensis y Fabaceae. En cuanto a la madera desecada, se han identificado 104 fragmentos 

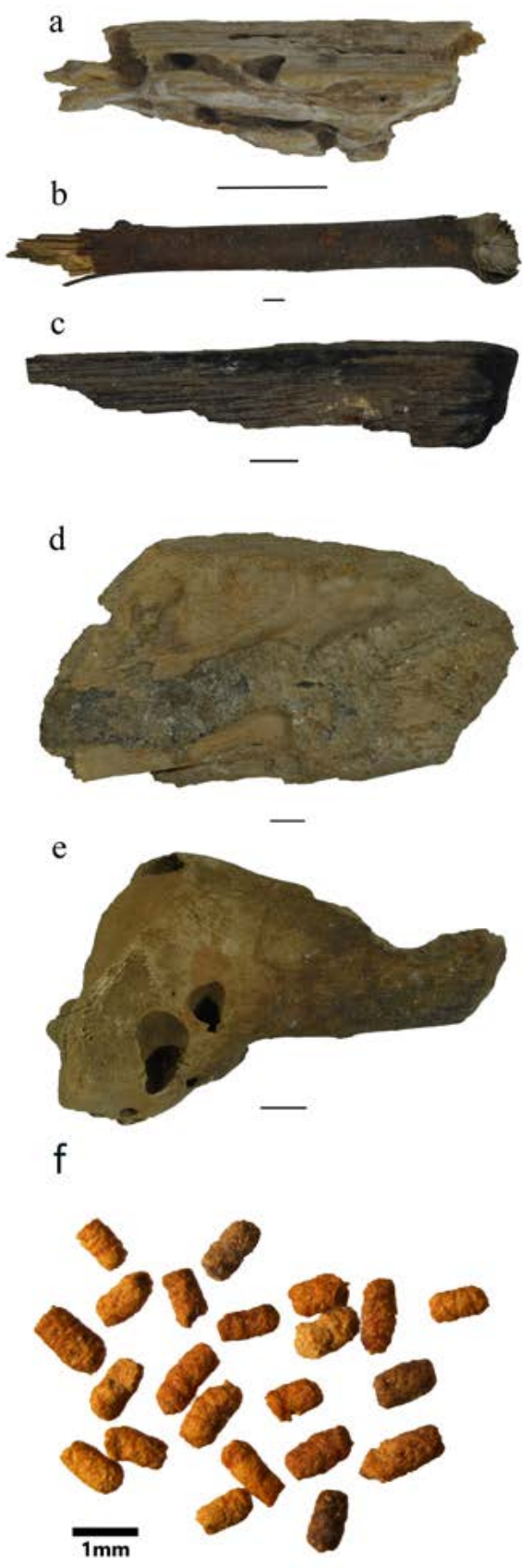

Fig. 6. Restos de maderas recuperados en el granero de Risco Pintado (Temisas): a. fragmento de dracaena bioalterada por xilófagos (S2. P2); b. Fracción de madera de fabácea leñosa (S2.P2); c. Fragmento de pino canario (Pinus canariensis) con evidencias de termoalteración (S7.P1); d. Pieza de madera de laurácea (S10.P1); e. Fragmento de madera de higuera (Ficus carica) con muestras de bioalteración muy avanzada como las galerías realizadas por xilófagos (S4.P1b); f. Restos de coprolitos de insectos, recuperados del interior de la madera de higuera anterior. S Silo, P Planta (en color en la versión electrónica). Escala gráfica: $1 \mathrm{~cm}$ salvo que se especifique otro valor. pertenecientes a 15 silos. El taxón más abundante es el pino canario, el cual está presente en todos los silos estudiados a excepción de Silo 3-Planta 2 y Silo 4 Planta 1 baja (porcentaje de ubicuidad de 86,6\%). Junto a este taxón se han documentado otros en los diferentes silos: Dracaena sp., Fabaceae, Ficus carica y Lauraceae. Con el objetivo de ofrecer una garantía en el grado de determinación de los taxones, algunos de ellos han sido determinados al rango de género (como el caso de Dracaena sp. donde no es posible discernir entre las especies $D$. draco y D. tamaranae) o al de familia (tanto las especies de leguminosas como las lauráceas presentes en Canarias no ofrecen criterios sólidos para poder identificar la especie con seguridad) (Jacquiot 1955; Jacquiot et al. 1973; Schweingruber 1990). Cabe indicar que las evidencias de biodeterioro por la acción de hongos, bacterias e insectos xilófagos están presentes en la mayoría de las maderas estudiadas, afectando en mayor medida a Pinus canariensis, Dracaena sp. y Ficus carica. Por último hay evidencias de alteración térmica en dos fragmentos de pino canario (S3.P1 y $\mathrm{S} 2 . \mathrm{P} 2)$ y uno de leguminosa leñosa (S7.P1).

\subsection{Los restos de insectos}

Se identificaron 4 especies en el interior de los silos (Fig. 7) (Tab. 3). El insecto más numeroso (número mínimo de 5427 individuos) es el gorgojo del grano (Sitophilus granarius), representando el 60,63\% de todas las evidencias entomológicas. Se ubica en la totalidad de los silos estudiados, con una densidad media de 159,61 insectos por silo. Destaca la concentración en el S3.P2 con 976 especímenes identificados. Este gorgojo se conserva generalmente fragmentado. El tórax es la parte más numerosa en el registro, debido a que está compuesto por un único segmento compacto. El abdomen comprende múltiples segmentos abdominales y élitros que se rompen con facilidad, lo mismo que la cabeza formada por apéndices (antenas, ojos y aparato bucal), lo que dificulta la identificación taxonómica.

El gorgojo del grano es un insecto sinantrópico que se ha expandido por todo el mundo a partir de la difusión de la agricultura y que se alimenta exclusivamente de cereal almacenado por los seres humanos, constituyendo una de las plagas más perjudiciales para estos granos (King 2014; King et al. 2014). No puede volar y su expansión se efectúa mediante el transporte e intercambio de semillas infectadas. Se adapta bien a climas templados, y su ciclo de vida dura entre 12 y 104 días, dependiendo de las condiciones en las que se desarrolle (Delobel y Tran 1993). Se considera una plaga primaria, ya que ataca directamente los granos, principalmente de trigo y cebada, 


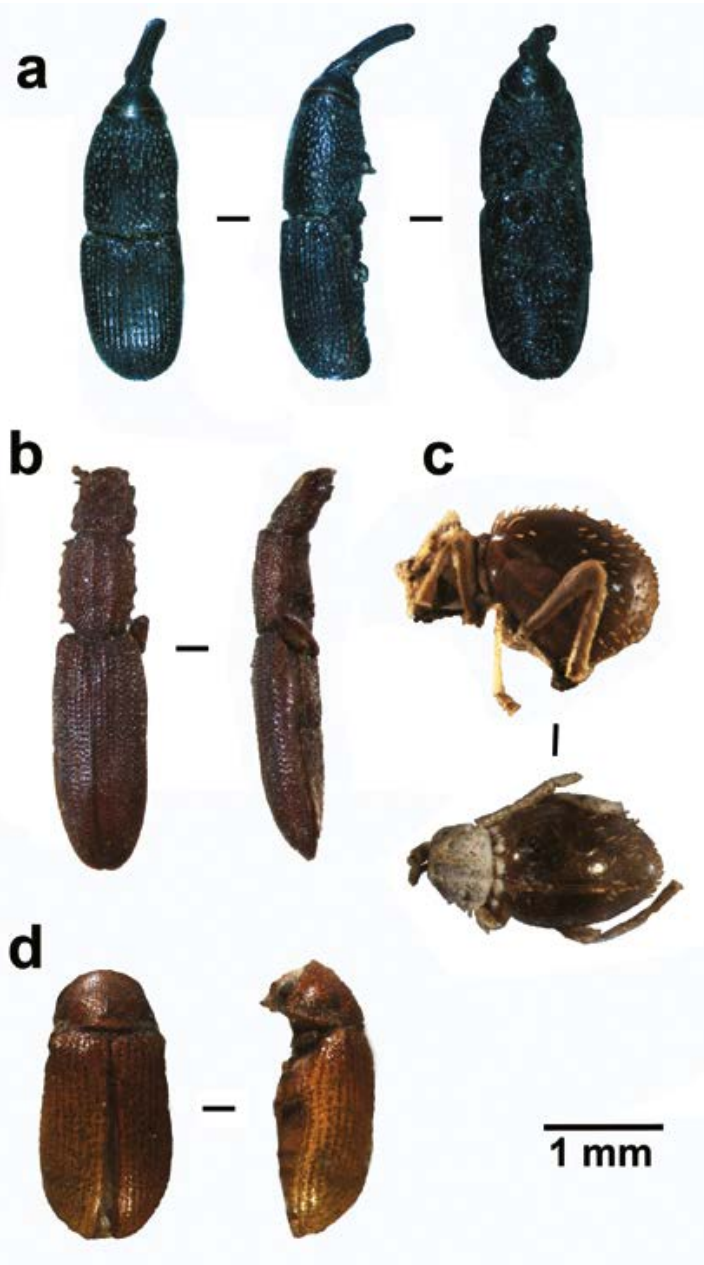

Fig. 7. Insectos recuperados en el granero de Risco Pintado (Temisas): a. gorgojo del grano (Sitophilus granarius); b. gorgojo dientes de sierra (Oryzaephilus surinamensis); c. escarabajo araña (Mezium americanum); d. gorgojo del pan (Stegobium paniceum). Fotos realizadas con una cámara Nikon DS-Fi 1 acoplada a una lupa binocular 8-80 X, y montadas con Helicon Focus (en color en la versión electrónica).

y atrae a otras especies que constituyen plagas secundarias (Buckland 1991; Huchet 2017). Solo pueden reproducirse en granos con una proporción de humedad superior al 9,5\% y en temperaturas entre $\operatorname{los} 13{ }^{\circ} \mathrm{C}$ y $\operatorname{los} 35^{\circ} \mathrm{C}$. Para ello, introducen un huevo en cada grano, realizando un pequeño agujero. Las larvas viven toda su vida en el interior hasta que eclosionan (Plarre 2010).

El escarabajo-araña (Mezium americanum), una plaga menor en los espacios de almacenamiento, representa con 921 individuos el 10,29\% de todos los insectos documentados en el granero. Aparece en 30 de los 34 silos estudiados, con una densidad de 30,7 individuos por silo. Se relacionan con la mala higiene de los mismos, al habitar sobre todo en los excrementos de aves y roedores. Pueden consumir cereales y harinas, frutas secas, pieles de animales, huesos y otros insectos muertos, así como madera vieja (Hagstrum y Subramanyam 2009).

El gorgojo dientes de sierra (Oryzaephilus surinamensis) constituye un 7,7\% de los insectos identificados. Los 689 especímenes contabilizados proceden de 24 silos. El tórax de este gorgojo posee los bordes aserrados, elemento diagnóstico de este taxón. Como el gorgojo del grano, el tórax es la parte más representativa de las muestras, al estar compuesta por una única fracción compacta.

Al igual que el gorgojo del grano, el escarabajo dientes de sierra es una especie sinantrópica (Huchet 2017). Se considera una plaga secundaria de los cereales, pues sólo consume los granos dañados, así como restos de comida sobre los que va depositando sus huevos. Los adultos tienen una esperanza de vida que va de los 6 meses hasta los 3 años. Se desarrollan en ambientes entre $17-35^{\circ} \mathrm{C}$ y con una humedad superior al $10 \%$ (Delobel y Tran 1993).

La cuarta especie identificada, el gorgojo del pan (Stegobium paniceum), es una plaga secundaria de los cereales, ya que es incapaz de dañar el grano intacto. Al igual que el gorgojo dientes de sierra, consume el grano ya dañado o cuando está procesado (convertido en harina). Ataca además otros materiales orgánicos como la carne y la leche (Gunasekaran y Rajendran 2005). Se han contabilizado 347 individuos $(3,87 \%$ de todos los insectos), localizados en 16 silos. Este gorgojo es capaz de volar por lo que pudo llegar al granero de diversas maneras. Algunos ejemplares estaban vivos, sugiriendo que su presencia en esos silos era reciente.

Estos resultados exponen los primeros datos arqueobotánicos y arqueoentomológicos recuperados del granero de Risco Pintado. Resta identificar una cantidad significativa de los insectos separados, en fase de estudio, incluidos en la Tabla 7 bajo la categoría de "Otros insectos". Es muy probable que dentro de esta categoría se encuentren otras especies identificadas como plagas, así como insectos no asociados con el almacenamiento, y que se introducirían en el silo tras su abandono.

\subsection{Dataciones radiocarbónicas}

El periodo de uso del granero se determinó mediante 7 dataciones radiocarbónicas (C14). Cinco fueron realizadas sobre materiales vegetales por Espectometría de Masas con Aceleradores (AMS) (Tab. 4): cuatro sobre segmentos de raquis de cebada 


\begin{tabular}{|c|c|c|c|c|c|c|c|c|}
\hline \multicolumn{2}{|c|}{ SILO } & \multirow{2}{*}{$\frac{\text { Sitophilus } g .}{12}$} & \multirow{2}{*}{$\frac{\text { Mezium a. }}{32}$} & \multirow{2}{*}{$\frac{\text { Stegobium } p \text {. }}{0}$} & \multirow{2}{*}{$\begin{array}{c}\text { Oryzaephilus s. } \\
8\end{array}$} & \multirow{2}{*}{$\begin{array}{c}\begin{array}{c}\text { Otros } \\
\text { insectos }\end{array} \\
76\end{array}$} & \multirow{2}{*}{$\begin{array}{c}\text { Pupas } \\
-\end{array}$} & \multirow{2}{*}{$\begin{array}{c}\begin{array}{c}\text { Total restos en } \\
\text { Silos }\end{array} \\
128\end{array}$} \\
\hline S 1 & P 1 & & & & & & & \\
\hline $\mathrm{S} 3 \mathrm{~A}$ & P 1 & 256 & 56 & 16 & 8 & 46 & - & 382 \\
\hline S 3 B & P 1 & 8 & 20 & 0 & - & 8 & - & 36 \\
\hline $\mathrm{S} 3 \mathrm{C}$ & P 1 & 40 & 8 & 32 & - & 4 & - & 84 \\
\hline S 4 & P 1 & 64 & 40 & - & 89 & 8 & 12 & 213 \\
\hline S 5 & P 1 & 392 & 52 & 54 & 8 & 74 & - & 580 \\
\hline S 6 & P 1 & 92 & 5 & - & 8 & 8 & - & 113 \\
\hline S 7 & P 1 & 48 & - & 20 & 8 & 9 & - & 85 \\
\hline S 8 & P 1 & 92 & - & 4 & - & 5 & 4 & 105 \\
\hline S 9 & P 1 & 284 & - & - & 8 & 48 & - & 340 \\
\hline S 10 & P 1 & 220 & - & - & 40 & 25 & 1 & 286 \\
\hline S 11 & P 1 & 136 & 6 & - & 40 & 4 & - & 186 \\
\hline S 12 & P 1 & 560 & 19 & 27 & 16 & 48 & 6 & 676 \\
\hline S 13 & P 1 & 100 & 32 & - & 8 & 16 & - & 156 \\
\hline S 14 & P 1 & 80 & 12 & - & - & 40 & 56 & 188 \\
\hline S 15 & P 1 & 132 & 48 & - & 16 & 32 & 3 & 231 \\
\hline S 16 & P 1 & 132 & 8 & - & 8 & 8 & - & 156 \\
\hline S 17 & P 1 & 64 & 45 & 4 & 8 & 32 & 4 & 157 \\
\hline S 18 & P 1 & 68 & 20 & 8 & 24 & 48 & - & 168 \\
\hline S 19 & P 1 & 172 & 76 & - & 16 & 108 & 4 & 376 \\
\hline S $20 \mathrm{~A}$ & P 1 & 116 & 44 & - & 8 & 12 & - & 180 \\
\hline S $20 \mathrm{~A}$ & P 1 & 112 & 24 & 4 & 16 & 20 & - & 176 \\
\hline S 1 & P 1b & 236 & 24 & - & - & 44 & 13 & 317 \\
\hline S 2 & P $1 b$ & 271 & 84 & 4 & 24 & 91 & - & 474 \\
\hline S 3 & P 1b & 36 & 4 & - & - & 28 & 6 & 74 \\
\hline S 4 & P $1 b$ & 40 & 8 & 1 & - & 5 & 1 & 55 \\
\hline S $5 \mathrm{~A}$ & P $1 b$ & 216 & 29 & - & 24 & 111 & 5 & 385 \\
\hline S $5 \mathrm{~B}$ & $\mathrm{P} 1 \mathrm{~b}$ & 84 & 12 & 48 & 16 & 4 & 2 & 166 \\
\hline $\mathrm{S} 5 \mathrm{C}$ & $\mathrm{P} 1 \mathrm{~b}$ & 156 & 8 & 5 & 8 & 56 & 4 & 237 \\
\hline S $5 \mathrm{D}$ & $\mathrm{P} 1 \mathrm{~b}$ & 68 & 12 & 80 & - & 20 & 64 & 244 \\
\hline S 1 & P 2 & 60 & 29 & - & - & 17 & 8 & 114 \\
\hline S 2 & P 2 & 84 & 48 & 8 & 96 & 74 & 25 & 335 \\
\hline S 3 & P 2 & 976 & 115 & 32 & 184 & 188 & 8 & 1503 \\
\hline S 4 & P 2 & 20 & 1 & - & - & 24 & - & 45 \\
\hline total & & 5427 & 921 & 347 & 689 & 1341 & 226 & 8951 \\
\hline$\% \mathrm{t}$ & & $60,63 \%$ & $10,28 \%$ & $3,87 \%$ & $7,69 \%$ & $14,98 \%$ & $2,52 \%$ & \\
\hline
\end{tabular}

Tab. 3. Número estimado de los restos de insectos identificados en Risco Pintado. En la columna "Otros" aparecen los que están en fase de estudio.

Trab. Prehist., 76, N. ${ }^{\circ}$ 1, enero-junio 2019, pp. 120-137, ISSN: 0082-5638

https://doi.org/10.3989/tp.2019.12229 


\begin{tabular}{|l|l|c|c|c|c|}
\hline Material & Nombre común & Localización & Código Lab. & $\begin{array}{c}\text { Datación } \\
\text { radiocarbónica BP }\end{array}$ & $\begin{array}{c}\text { Fecha calibrada } \\
\text { d.C. }\end{array}$ \\
\hline Oryzaephilus surinamensis & Dientes de sierra & Silo 3-P2 & Beta - 469049 & $1100 \pm 30$ & $886-1013$ \\
\hline Sitophilus granarius & Gorgojo & Silo 3-P2 & Beta - 469050 & $960 \pm 30$ & $1020-1155$ \\
\hline Hordeum vulgare & Cebada & Silo 3-P2 & Beta - 362111 & $860 \pm 30$ & $1050-1250$ \\
\hline Hordeum vulgare & Cebada & Silo 1-P2 & Beta - 362110 & $610 \pm 30$ & $1290-1410$ \\
\hline Hordeum vulgare & Cebada & Silo 8-P1 & Beta - 362112 & $550 \pm 30$ & $1320-1430$ \\
\hline Hordeum vulgare & Cebada & Silo 12-P1 & Beta - 362113 & $520 \pm 30$ & $1330-1440$ \\
\hline Laurus novocanariensis & Laurel & Silo 1-P1 & Beta - 362109 & $510 \pm 30$ & $1400-1440$ \\
\hline
\end{tabular}

Tab. 4. Dataciones obtenidas sobre material vegetal e insectos procedentes de 6 silos de Risco Pintado.

y una sobre un fragmento de hoja de laurel. Los resultados obtenidos han aportado unas fechas que oscilan entre los intervalos 1050-1080 cal AC y 14001440 cal AC.

Para confirmar la simultaneidad de las plagas y los restos vegetales se fecharon además dos muestras, una de gorgojo del grano y otra de gorgojo dientes de sierra, procedentes del S3.P2. Se utilizaron varios especímenes para cada muestra con el fin de alcanzar el peso adecuado para los análisis. Los resultados situaron la antigüedad de la muestra de los gorgojos del grano en el intervalo temporal 1020-1155 cal AC y la de gorgojo dientes de sierra entre 886-1013 cal AC.

Para confirmar la compatibilidad temporal de insectos y semillas un fragmento de cebada datado, procedía del mismo silo que los insectos, acreditando una antigüedad de 1050-1250 cal AC. Para obtener una visión gráfica, estas fechas fueron combinadas con la función R-Combine de OxCal versión 4.3.2. (Bronk Ramsey 2017) (Fig. 8).

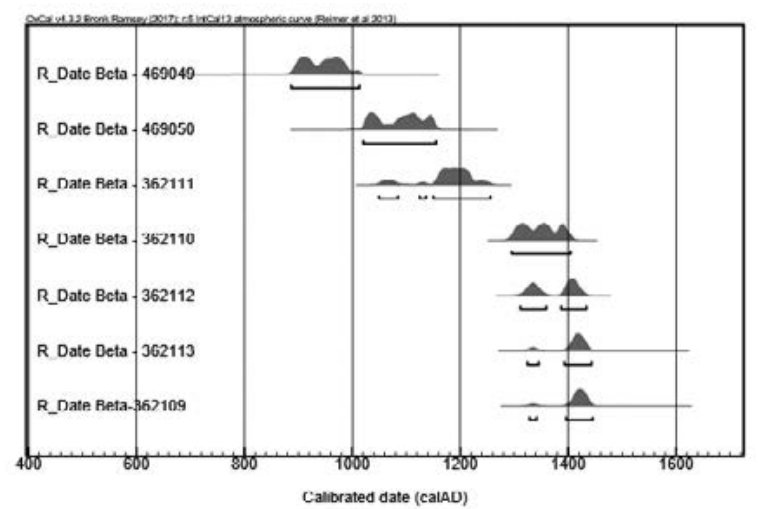

Fig. 8. Gráfico con las dataciones calibradas (cal DC) de las fechas sobre muestras de insectos y semillas procedentes del granero de Risco Pintado (Temisas, Gran Canaria), utilizando OxCal versión 4.3.2. (Bronk Ramsay 2001; Reimer et al. 2013; Bronk Ramsay 2017).

\section{DISCUSIÓN}

\subsection{Las especies almacenadas}

Los resultados obtenidos en el análisis de los restos vegetales han permitido identificar algunas de las plantas almacenadas en los silos del granero de Risco Pintado. Las especies más abundantes son la cebada y el higo. El total de evidencias de este último taxón es más elevado que el de la cebada, pero recordemos que, como un higo puede contener cientos de semillas, su número está sobrerrepresentado con respecto al cereal. El índice de ubicuidad de la cebada es más elevado (solo falta en un silo). Además, la presencia en estos silos de gorgojos del grano, que sólo se alimentan de cereal almacenado, sugiere que la cebada constituía el principal producto depositado y a la vez que su conservación a largo plazo estaba en riesgo.

El número total de restos de trigo y su dispersión por los silos sugiere que su papel fue menos significativo entre los productos almacenados. Ello respaldaría la idea (Morales 2010; Morales et al. 2014, 2017), de que el trigo tuvo un papel secundario con respecto a la cebada en la agricultura aborigen. Lo mismo sucede con las legumbres y con las plantas silvestres, las cuales presentan un número limitado y una distribución irregular por los silos.

Un patrón similar en cuanto a número de restos y distribución en los silos ha sido identificado en el granero de Acusa, donde cebada e higo constituyen las evidencias botánicas más abundantes (Morales et al. 2014). Este mismo patrón es observable en los restos carpológicos, preservados por carbonización, obtenidos en contextos domésticos del mismo periodo en la isla de Gran Canaria (Morales 2010; Morales et al. 2017). En ellos, las semillas de cebada e higo son también más comunes que los restos de trigo, legumbres y plantas recolectadas, mucho más reducidos (Tab. 5). La información etnohistórica proporcionada por los primeros viajeros europeos que llegaron al archipiélago entre los 


\begin{tabular}{|c|c|c|c|c|c|c|c|c|}
\hline & $\begin{array}{c}\text { La } \\
\text { Cerera }\end{array}$ & EI Tejar & $\begin{array}{l}\text { Ermita } \\
\text { de San } \\
\text { Antón } \\
\end{array}$ & $\begin{array}{l}\text { Lomo los } \\
\text { Melones }\end{array}$ & $\begin{array}{l}\text { Cueva } \\
\text { Pintada }\end{array}$ & $\begin{array}{c}\text { Lomo los } \\
\text { Gatos }\end{array}$ & $\begin{array}{l}\text { El Álamo- } \\
\text { Acusa }\end{array}$ & $\begin{array}{c}\text { La } \\
\text { Audiencia- } \\
\text { Temisas } \\
\end{array}$ \\
\hline Funcionalidad & \begin{tabular}{|c|} 
Cueva/ \\
Vivienda
\end{tabular} & $\begin{array}{c}\text { Ritual/ } \\
\text { Vivienda }\end{array}$ & $\begin{array}{l}\text { Cocina/ } \\
\text { Mixto }\end{array}$ & Vivienda & $\begin{array}{l}\text { Poblado/ } \\
\text { Vivienda }\end{array}$ & Mixto & Granero & Granero \\
\hline Preservación & Carb. & Carb. & Carb. & Carb. & Carb. & Carb. & Desec. & Desec. \\
\hline Cronología d.C. & VI-XV & VI-XV & XIII-XIV & XIII-XV & VII-XVI & XV-XVII & XI-XV & IX-XV \\
\hline Volumen sedimento & 780 & 617 & 69 & 491 & 737 & 207 & 14 & 34 \\
\hline $\begin{array}{l}\text { Densidad semillas por } \\
\text { litro de sedimento }\end{array}$ & 1,17 & 0,21 & 1,42 & 5,86 & 4,59 & 2,38 & 836,85 & 343,54 \\
\hline \multicolumn{9}{|l|}{ Plantas cultivadas } \\
\hline $\begin{array}{l}\text { Hordeum vulgare, } \\
\text { grano/gluma articulada }\end{array}$ & 880 & 92 & 17 & 212 & 1465 & 245 & 952 & 154 \\
\hline Hordeum vulgare, raquis & 3 & 3 & 2 & 4 & 90 & - & 5795 & 570 \\
\hline $\begin{array}{l}\text { Triticum aestivium/ } \\
\text { durum, grano }\end{array}$ & 2 & 3 & 2 & 3 & 216 & 49 & 2 & 6 \\
\hline Triticum durum, raquis & - & - & - & - & 1 & - & 403 & 40 \\
\hline Nudos de cereal & - & - & - & - & 1 & - & 7 & 76 \\
\hline Lens culinaris & 1 & - & 21 & - & 7 & - & 61 & 49 \\
\hline Pisum sativum & 1 & - & - & - & 3 & - & 1 & - \\
\hline Vicia faba & - & - & - & - & 2 & - & 14 & 7 \\
\hline Ficus carica, endocarpo & 25 & 32 & 53 & 2658 & 1581 & 108 & 4458 & 2955 \\
\hline Ficus carica, fruto & - & - & - & - & 1 & 9 & 8 & 9 \\
\hline \multicolumn{9}{|l|}{ Plantas recolectadas } \\
\hline $\begin{array}{l}\text { cf. Adenocarpus } \\
\text { foliolosus }\end{array}$ & - & - & - & - & 1 & - & - & \\
\hline $\begin{array}{l}\text { cf. Laurus } \\
\text { novocanariensis }\end{array}$ & - & - & - & - & - & - & 3 & 8 \\
\hline $\begin{array}{l}\text { Neochamaelea } \\
\text { pulverulenta }\end{array}$ & - & - & 3 & - & 3 & 3 & - & - \\
\hline Phoenix canariensis & 2 & 3 & - & 1 & 2 & 21 & 4 & 11 \\
\hline Pinus canariensis & - & - & - & - & - & - & 8 & 1 \\
\hline $\begin{array}{l}\text { Pistacia atlantical } \\
\text { lentiscus }\end{array}$ & - & 1 & - & - & 1 & - & - & 2 \\
\hline Plocama pendula & - & - & - & 1 & - & 55 & - & - \\
\hline Retama rhodorhizoides & - & - & - & - & 1 & - & - & - \\
\hline Rubus sp. & - & - & - & - & 1 & - & - & - \\
\hline Total de restos & 914 & 134 & 98 & 2879 & 3376 & 490 & 11716 & 3888 \\
\hline
\end{tabular}

Tab. 5. Número estimado de plantas cultivadas y silvestres estudiadas en contextos domésticos de Gran Canaria (Morales 2010), junto con las evidencias de Álamo-Acusa (Morales et al. 2014) y de Risco Pintado. Carb = carbonizado; Desc = desecado.

siglos XIV y XVI subraya la importancia de la cebada y los higos en la dieta de la población indígena de Gran Canaria y corrobora los datos aquí obtenidos (Abreu Galindo 1977; Morales Padrón 2008).

La única excepción es que en los lugares de almacenamiento el número de los raquis de cereal y las vainas de leguminosas es muy superior al que hay en los contextos domésticos. Esto podría indicar la práctica de actividades de procesado de los productos vegetales diferenciadas en función de si se pretende conservar los vegetales a largo plazo en los graneros o si se van a consumir en el ámbito doméstico (Sigaut 1981).

Las dataciones radiocarbónicas indican que este espacio de almacenamiento estuvo en uso entre los siglos XI y XV. No obstante, las fechas entre los siglos IX y XI obtenidas sobre los gorgojos de dientes de sierra son ligeramente anteriores e implican que el granero pudo haber estado funcionando al menos desde este periodo. Las evidencias de gorgojos no son visibles a simple vista, $y$ es probable que no fueran 
detectados ni eliminados durante las retiradas de cereal y las limpiezas de los silos realizadas durante su uso.

En el marco del proyecto de investigación que estamos desarrollando, se han realizado varias series de dataciones en distintos graneros de Gran Canaria. Los datos disponibles hasta el momento son coincidentes para todos ellos y apuntan a su máximo desarrollo en el periodo comprendido entre los siglos XI y XV d. C. Por el momento disponemos de los datos de los sitios de Acusa (término municipal de Artenara), Cuevas Muchas (término municipal de Ingenio) y el Cenobio de Valerón (término municipal de Santa María de Guía). Las fechas obtenidas en Acusa fueron realizadas sobre materiales vegetales y gorgojos del grano, e indican que el granero estuvo en uso al menos entre los siglos XI y XV d. C. (Morales et al. 2014). En el granero de Cuevas Muchas un conjunto de cinco dataciones sobre restos vegetales ha aportado fechas comprendidas entre los siglos XIII y XV (Hagenblad et al. 2017). En el Cenobio de Valerón se dataron 5 muestras de cebada e higo que aportaron unas fechas comprendidas entre los siglos XI y XV (Naranjo y Rodríguez 2015). Existe una datación procedente de una semilla carbonizada del granero de La Montañeta con una fecha comprendida entre los siglos VII y XIV (Morales et al. 2018). Los graneros carecen de estructuras de combustión, por lo que es probable que los restos carbonizados procedan de las argamasas que cubrían el silo. En ellas se documentan restos de semillas y de otros vegetales carbonizados que, con mucha probabilidad, pueden representar desperdicios domésticos reutilizados para confeccionar este elemento constructivo. Es decir, esa semilla puede estar aportando una fecha más antigua que la del uso real de los silos.

En todo caso, aunque los graneros fueran usados antes del siglo XI, como sugieren las dataciones en el granero de la Montañeta, es evidente que adquieren su mayor importancia durante la primera mitad del II milenio d. C. Es posible que esa circunstancia sea resultado de un incremento de la actividad y la producción agrícola, lo que implicaría la necesidad de contar con mayores espacios de almacenamiento. El estudio previo de los restos carpológicos procedentes de contextos domésticos también apuntaba a la intensificación de la producción agrícola en aquellos yacimientos datados en el II milenio, en especial aquellos situados entre los siglos XIII y XV (Morales 2010).

\subsection{La existencia de plagas}

Las fuentes etnohistóricas mencionan el uso de los graneros por la población indígena de Gran Canaria cuya finalidad era, entre otras, conservar las semillas por un largo periodo de tiempo, evitando que fuesen atacadas por los gorgojos. Uno de los documentos menciona: "Tenian silos en los riscos i conservaba el grano muchos años sin dañarse, lo qual ahora no puede conseguirse sin que se pique de gorgojo" (Gómez Escudero, en Morales Padrón 2008: 436). No obstante, hemos comprobado que la población tuvo que lidiar con dos de las principales plagas que se desarrollan en torno al ensilado: el gorgojo del grano y el gorgojo dientes de sierra. La presencia en las muestras del escarabajo araña y del gorgojo del pan en un buen estado de conservación, siendo insectos con un exoesqueleto blando, propenso al rápido deterioro, podría interpretarse como intrusiones modernas. Por ello, no son discutidas en esta sección, sin menoscabo de que futuros estudios interpreten que también afectaron a los alimentos en época prehispánica.

Las dataciones sobre muestras de gorgojos del grano y gorgojos dientes de sierra han demostrado que estas especies fueron plagas coetáneas al almacenamiento de los productos vegetales. La datación sobre gorgojo del grano realizada en el yacimiento de Acusa, aportó una fecha similar a las obtenidas para esta especie en Risco Pintado: $980 \pm 30$ BP (1020-1150 cal DC) (Morales et al. 2014), lo que sugiere que esta plaga estaba extendida por distintos graneros de la isla. Los hallazgos de Risco Pintado constituyen el primer registro de gorgojo dientes de sierra en yacimientos arqueológicos del archipiélago canario. Como ambas especies de gorgojos son sinantrópicas e incapaces de volar, su aparición en Canarias debe atribuirse a los primeros colonos, quienes, sin saberlo, transportaron los huevos de ambos insectos en las semillas y otros alimentos que llevaron consigo.

Los gorgojos del grano son un grave problema para el almacenamiento a largo plazo de cereales. Al haberse adaptado a la vida en los graneros son una de las plagas más extendidas por el planeta (Delobel y Tran 1993). Su aparición se constata desde el Neolítico, cuando los humanos empiezan a cultivar cereales y almacenar mayores cantidades de alimentos (Buckland 1991; Kuijt y Finlayson 2009; Plarre 2010). En Risco Pintado, se ha documentado un número mínimo de 5427 individuos, procedentes de todos los silos muestreados. Asimismo, más de trescientas glumas articuladas de cebada registradas presentan marcas de haber sido picadas por gorgojos (Fig. 4). El grano entero se conserva en muy contadas ocasiones, puesto que el gorgojo pone su huevo dentro del grano, y este al crecer, consume el endosperma, dejando únicamente la gluma (Longstaff 1981).

El gorgojo dientes de sierra es una de las plagas más importantes de los productos almacenados. También se distribuye por todo el planeta y se documenta desde el Neolítico (Delobel y Tran 1993; Huchet 2017). Su presencia en Risco Pintado es muy signifi- 
cativa, ya que es una plaga secundaria que sólo consume granos que han sido dañados por plagas primarias, como los gorgojos del grano. Se alimenta de productos de molienda, semillas, frutas blandas como los higos, y de otros insectos, sobre todo cuando compite con el gorgojo del grano (Trematerra et al. 2000).

La aparición de ambas plagas dentro del granero de Risco Pintado apunta a un uso efectivo de los silos para el almacenamiento a largo plazo de cereales y otros alimentos vegetales. El principal indicador es el gorgojo dientes de sierra, ya que sólo se desarrolla cuando los granos han sido afectados por plagas primarias o presentan malas condiciones de higiene, lo que sucede con mayor probabilidad cuando son almacenados a largo plazo. Además, el ciclo de vida de estas plagas (entre 3 meses para gorgojo del grano y 3 años para dientes de sierra) (Delobel y Tran 1993) indicaría que los silos sirvieron, probablemente, para almacenar alimentos durante un periodo de tiempo que supera el ciclo anual de las cosechas.

\subsection{Los métodos de almacenamiento}

La población indígena de Gran Canaria practicó una serie de técnicas encaminadas a proteger las semillas y evitar las plagas. Así, el uso de silos excavados en la toba volcánica es una estrategia tendente a mantener la temperatura y humedad de los granos a un nivel constante. Ya se ha mencionado que los huevos de los gorgojos eclosionan con una humedad superior al $10 \%$ y temperaturas comprendidas entre los $13{ }^{\circ} \mathrm{C}$ y $35^{\circ} \mathrm{C}$ (Delobel y Tran 1993; Plarre 2010). Así, el control de la temperatura y la humedad en valores bajos es esencial para evitar la proliferación de insectos dentro de las cavidades. No obstante, también favorece que los hongos colonicen la madera utilizada para acondicionar este espacio. Para evitarlo, la población prehispánica construyó los graneros en cuevas artificiales, que de forma natural mantienen la temperatura y humedad a un nivel constante (Culver y Pipan 2009; Bescherer y Beaudry 2015). En la actualidad todos los silos están descubiertos, pero durante las prospecciones y excavaciones realizadas en la primera mitad del siglo XX se hallaron las puertas de madera que los cubrían, en la actualidad expuestas en El Museo Canario (Onrubia 2003). Así mismo, en el granero del Cenobio de Valerón, hay planchas de fonolita de gran tamaño con los bordes retocados para adaptarlos posiblemente a la boca de los silos y facilitar su sellado (Naranjo y Rodríguez 2015). Esta diferencia implicaría quizás estrategias de almacenamiento heterogéneas, vinculadas a los sistemas de propiedad de cada cavidad y a la frecuencia de su apertura. Los silos con puertas con mucha probabilidad estarían expuestos a la circulación del aire, por lo que los granos no estarían confinados en una atmósfera sin oxígeno. La aireación o ventilación es importante para refrescar el espacio y evitar que los hongos afecten los productos almacenados, y está especialmente indicada cuando los granos se almacenan dentro de la espiga (Sigaut 1988).

Precisamente, las evidencias recuperadas en el granero de Risco Pintado indican que los granos eran almacenados dentro de su cubierta vegetal. La alta concentración de raquis y el escaso número de granos de cebada y de trigo en los silos está indicando que ambos cereales fueron almacenados sin procesar. Incluso a veces los segmentos de raquis están aún articulados y muestran el raquis basal, así como parte del tallo. En ellos se aprecian las marcas de corte donde la espiga es separada del resto de la planta (Fig. 4). Este patrón también ha sido registrado en el granero de Acusa, cuyas mejores condiciones de preservación han permitido que se conserven algunas espigas completamente articuladas (Morales et al. 2014). La documentación etnohistórica corrobora estas evidencias, al mencionar que los indígenas de Gran Canaria cosechaban los cereales arrancando la espiga y dejando el resto de la planta en el campo (Abreu Galindo 1977; Morales Padrón 2008; Morales 2010; Santana et al. 2012).

La técnica de conservación de los cereales en la espiga, con su cubierta vegetal, protege los granos de insectos y roedores, a la vez que permite mantener las condiciones de humedad y temperatura necesarias para su correcta conservación (Sigaut 1988). Estudios experimentales con cereales sin procesar y almacenados en la espiga indican que éstos son más resistentes a las plagas que aquellos conservados tras ser procesados (MeurersBalke y Lüning 1992; Alonso 1999). Es posible que la misma técnica se utilizara para almacenar las legumbres, ya que se han registrado restos de la vaina de lentejas y habas en varios silos de Risco Pintado, al igual que en el granero de Acusa (Morales et al. 2014). El hallazgo de fragmentos del raquis y del perianto de dátiles de palmera canaria sugiere que los frutos eran almacenados en las propias ramillas. En Risco Pintado los higos eran almacenados como frutos enteros según las evidencias arqueológicas y los documentos etnohistóricos, que mencionan la práctica de secar los higos para almacenarlos durante todo el año (Abreu Galindo 1977: 161). En todos los casos mencionados, la cubierta vegetal natural protege los granos y frutos sin que se advierta interés en procesar los granos para eliminar las impurezas y maximizar el volumen de almacenamiento.

Por último, las hojas y madera de laurel canario (Laurus novocanariensis) y las semillas de lentisco (Pistacia lentiscus) pudieron ser empleadas en los silos como repelentes e insecticidas. Las hojas y frutos del laurel canario contienen aceites esenciales que actúan 
como insecticidas y repelentes, a la vez que inhiben el crecimiento de las semillas e impiden la proliferación de hongos (Rodilla et al. 2008). El aceite esencial del laurel se encuentra en sus hojas y en sus frutos. Se conoce como insecticida desde la antigüedad, al menos el procedente del laurel común (Laurus nobilis) (Panagiotakopulu et al. 1995), y aún se sigue usando en el Mediterráneo (Mediouni et al. 2012; Halstead et al. 2014). Fragmentos de hojas de laurel canario también han sido documentadas en Acusa (Morales et al. 2014). En la actualidad, las hojas de laurel se usan en Canarias para evitar insectos en las despensas (Rodilla et al. 2008). Teniendo en cuenta esto, los fragmentos de madera identificados como Lauraceae pueden ser interpretados como los restos de ramas verdes de laurel con las hojas todavía insertas depositadas en los silos para evitar el desarrollo de plagas. El hecho de que los restos de madera de laurácea hayan sido detectados en silos diferentes a los que albergaban fragmentos de hojas de esta planta puede deberse a un factor de conservación. No obstante, no podemos descartar el uso de este taxón para confeccionar utensilios o acondicionar el espacio.

Por su parte, el lentisco tiene también propiedades repelentes, insecticidas y antifúngicas (Bougherra et al. 2015). El aceite esencial, concentrado en sus hojas y frutos, se usa para combatir plagas asociadas a los graneros y es especialmente eficaz en la eliminación de huevos de insectos (Bachrouch et al. 2010; Bougherra et al. 2015).

En ninguno de los silos muestreados existen pruebas de la acción del fuego que pudieran vincularse a su uso tradicional para combatir las plagas (Hakbijl 2002) (no hay cenizas o trazas de alteración térmica en el conjunto del granero). Esta ausencia no carece de lógica, pues podría constituir un peligro para la integridad de los contenidos custodiados en las diversas cámaras. Por tanto, los escasos fragmentos de carbones recuperados deben interpretarse como inclusiones en los restos de argamasa asociados a las paredes de los silos.

\section{CONCLUSIONES}

Este estudio aporta información significativa en el marco del proyecto que estamos realizando sobre las estrategias empleadas en el almacenamiento prehispánico en Gran Canaria, utilizando una metodología novedosa que combina el análisis de los restos vegetales y entomológicos. Los resultados obtenidos en el granero de Risco Pintado han aportado datos sobre las especies almacenadas, las plagas que afectaban a estos productos, y las técnicas de almacenamiento. No obstante, el número de graneros estudiados es por ahora muy escaso y se necesitan más análisis en otros espa- cios para tener una visión más completa sobre nuestro objeto de estudio. Además, es necesario realizar una serie más larga de dataciones, para contextualizar mejor este tipo de espacios y detectar las especies tanto vegetales como de insectos introducidas en los almacenes durante el periodo prehispánico. Por el momento, solo existe un trabajo sobre las industrias líticas, que apunta a que quizá en los graneros se procesara una parte de lo almacenado antes de transportarse a los contextos domésticos. También sugiere que se almacenaran productos que no se han conservado, como la carne, ya que algunos instrumentos localizados tienen huellas de su uso sobre esta materia. Por lo tanto, el análisis de los restos óseos de fauna y microfauna, de fragmentos de recipientes de piel, vegetales y cerámicos, así como de las maderas no carbonizadas encontradas en el interior de los silos, ilustrará mejor los aspectos ligados a la forma en que se guardaba cada tipo de producto, y hasta podría ayudar a conocer cómo se articulaba el espacio en los almacenes.

El presente estudio muestra que, aunque permanecieran abiertos tras su abandono, los silos prehispánicos de Risco Pintado conservan en buen estado parte de la cosecha de los antiguos canarios. Y ello a pesar de que una serie de plagas de carácter primario y secundario (esta última, identificada por primera vez en un yacimiento canario en Risco Pintado) mermaran en gran parte la cosecha almacenada.

Toda esta información confirma que los graneros prehispánicos de Gran Canaria muestran unas condiciones de conservación excepcionales y que exhiben un enorme potencial para contribuir al estudio del almacenamiento en el pasado.

\section{AGRADECIMIENTOS}

El trabajo realizado por Alisios Actividades aseguró el acceso al yacimiento. La empresa Tibicena S.L. y el Dr. Ernesto Martín colaboraron en la documentación gráfica del granero. Agradecemos al Jardín Botánico Canario "Viera y Clavijo" y al Centro Instrumental Químico-Físico para el Desarrollo de la Investigación Aplicada de la Universidad de las Palmas de Gran Canaria (CIDIA, ULPGC) su disposición para la creación de la colección de referencia de maderas actuales de Canarias.

\section{BIBLIOGRAFÍA}

Abreu Galindo, J. 1977: Historia de la conquista de las siete Islas de Canaria. Ed. Goya. Madrid.

Alonso i Martínez, N. 1999: De la llavor a la farina. Els processos agrícolas protohistòrics a la Catalunya occidental. Monographies d'Archéologie Méditerranéenne 4, CNRS. Lattes. 
Alonso Martínez, N.; Juan Tresserras, J.; Rodríguez-Ariza, M. O. y Rovira Buendía, N. 2000: "Muestreo arqueobotánico de yacimientos al aire libre y en medio seco". En R. Buxó y R. Piqué (eds.): $L a$ recogida de muestras en arqueobotánica: objetivos y propuestas metodológicas. La gestión de los recursos vegetales y la transformación del paleopaisaje en el Mediterráneo occidental. Encuentro del grupo de trabajo de arqueobotánica de la Península Ibérica. Barcelona/Bellaterra:29-46. http://bioarqueologia.cat/upload/files/recogidamuestrasarqueobotanica.pdf (consulta 15-12-2017)

Angus, R. y Ribera, I. 1996: "Entomología del Cuaternario". Boletín Sociedad Entomológica Aragonesa 16, Monográfico Paleoentomología: $175-182$.

Arco Aguilar, M. C. del; Arco Aguilar, M. M. del; Benito Mateo, C. y Rosario Adrián, M. C. 2017: Un taller romano de púrpura en los límites de la Ecúmene. Lobos I (Fuerteventura, Islas Canarias). Primeros resultados. Museo de Naturaleza y Hombre, Cabildo de Tenerife. Santa Cruz de Tenerife.

Arroyo, J.; Riva Caballero, A. de la; Iturrondobeitia, J. C.; Bermúdez de Castro, J. M.; Carbonell, E.; Arsuaga, J. L. y Díez, C. 2007: "Primera aproximación a la Paleoentomología de los yacimientos de la Sierra de Atapuerca (Burgos, España): la fauna subfósil de Oribátidos (Acari, Oribátida)”. Graellsia 63 (1): 27-34. https://doi.org/10.3989/graellsia.2007.v63.i1.77

Bachrouch, O.; Mediouni-Ben Jemaa, J.; Waness Wissem, A.; Talou, T.; Marzouk, B. y Abderraba, M. 2010: "Composition and insecticidal activity of essential oil from Pistacia lentiscus L. against Ectomyelois ceratoniae Zeller and Ephestia kuehniella Zeller (Lepidoptera: Pyralidae)". Journal of Stored Products Research 46 (4): 242-247. https://doi.org/10.1016/j.jspr.2010.07.001

Badal, E. y Heinz, C. 1991: Méthodes utilisées en Anthracologie pour l'étude de sites préhistoriques. BAR International Series 573, 17-47.

Bescherer, K. y Beaudry M. C. 2015: Archaeology of Food: An Encyclopedia. Ed. Rowman y Littlefield. Londres.

Bronk Ramsey, C. 2001: "Development of the radiocarbon calibration program". Radiocarbon 43 (2): 355-363. https://doi.org/10.1017/s0033822200038212

Bronk Ramsey, C. 2017: "Methods for summarising radiocarbon datasets". Radiocarbon 59 (6): 1-33. https://doi.org/10.1017/rdc.2017.108

Bougherra, H.; Bedini, S.; Flamini, G.; Cosci, F.; Belhamel, K. y Conti, B. 2015: "Pistacia lentiscus essential oil has repellent effect against three major insect pests of pasta". Industrial Crops and Products 63: 249-255. https://doi.org/10.1016/j.indcrop.2014.09.048

Buckland, P. C. 1991: "Insects, granaries and stores: the Archaeology of Insect Synanthropy”. La préparation alimentaire des céréales 26 (septiembre): 69-81.

Buckland, P. I.; Buckland, P. C. y Olsson, F. 2014: "Paleoentomology: insects and other arthropods in environmental archaeology". En C. Smith (ed.): The encyclopedia of global archaeology. Springer Science \& Bussines Media B.V: 5740-5755.

Chabal, L.1997: Forêts et sociétés en Languedoc (Néolithique final, Antiquité tardive): l'anthracologie, méthode et paléoécologie. Éditions de la Maison des Sciences de l'Homme. París.

Coope G. R. y Osborne P. J. 1968: "Report on the coleopterous fauna of the Roman well at Barnsley Park, Gloucestershire". Transactions of the Bristol and Gloucestershire Archaeological Society 86: 84-87

Cranston, P. J. y Gullan, P. S. 1994: Insects: an outline of Entomology. Ed. Chapman \& Hall. 4a. London.

Cuenca Sanabria, J. 2014: "Detenido en el tiempo: Los nuevos hallazgos de Risco Pintado - La Audiencia”. Boletín electrónico de Patrimonio Histórico 2: 35-38. http://cabildo.grancanaria.com/rhtml/patrimonio_historico/boletin_e_2/archivos/09-detenido-tiempo.pdf (consulta 15-10-2017).

Culver, D. C. y Pipan T. 2009: The biology of caves and other subterranean habitats. Oxford University Press. New York.

Delaigue, M. C. ; Onrubia Pintado, J.; Bokbot, Y. y Amarir, A. 2011: "Une technique d'engrangement, un symbole perché. Le grenier fortifié Nord-Africain". Techniques \& Culture 57 (2): 182-201. https://doi.org/10.4000/tc.5875

Delgado-Darias, T. 2009: La historia de los dientes - una aproximación a la Prehistoria de Gran Canaria desde la Antropología Dental. Ed. Cabildo de Gran Canaria. Las Palmas de Gran Canaria.
Delobel, A. y Tran, M. 1993: Les coléoptères des denrées alimentaires entreposées dans les régions chaudes. Ed. Orstom. París

Gunasekaran, N. y Rajendran, S. 2005: "Toxicity of carbon dioxide to drugstore beetle Stegobium paniceum and cigarette beetle Lasioderma serricorne". Journal of Stored Products Research 41 (3): 283-294. https://doi.org/10.1016/j.jspr.2004.04.001

Hagenblad, J.; Morales, J.; Leino, M. y Rodríguez-Rodríguez, A. 2017: "Farmer fidelity in the Canary Islands revealed by Ancient DNA from prehistoric seeds". Journal of Archaeological Science 78: 78-87. https://doi.org/10.1016/j.jas.2016.12.001

Hagstrum, D.W. y Subranabyam, B. 2009: Stored-Product Insec Resource. $1^{\mathrm{a}}$ ed. Advancing Grain Science Worldwide. Minnesota, USA.

Hakbijl, T. 2002: "The traditional, historical and prehistoric use of ashes as an insecticide, with an experimental study on the insecticidal efficacy of washed ash". Environmental Archaeology 7 (1): 13-22. https://doi.org/10.1179/146141002790556793

Halstead, Paul. 2014: Two Oxen Ahead: Pre-Mechanized Farming in the Mediterranean. Ed. John Wiley \& Sons Ltd. $1^{\text {a }}$ ed. Pondicherry, India.

Huchet, J. B. 2017: "Le coléoptère, la graine et l'archéologue: approche archéoentomologique de quelques ravageurs des denrées stockées". En M.-F. Diestch-Sellami, Ch. Hallavant, L. Bouby, B. Pradat (eds.): Plantes, produits végétaux et ravageurs. Actes des $X$ Recontres d'Archéobotanique (Les Eyzies-de-Tayac 2014). Aquitania, supplément 36. Burdeos: 17-42.

Jacquiot, C. 1955: Atlas d'anatomie des bois des conifères. Centre technique du bois. Paris.

Jacquiot, C.; Trenard, Y. y Dirol, D. 1973: Atlas d'anatomie des bois des angiospermes (Essences feuillues). Centre technique du bois. Paris.

Jiménez González, J. J. 1998: "Las fuentes etnohistóricas canarias. Crónicas, historias, memorias y relatos". Anuario de Estudios Atlánticos 44: 199-263.

Jiménez Sánchez, S. 1952: Yacimientos arqueológicos grancanarios descubiertos y estudiados en 1951. Faycan. Las Palmas de Gran Canaria.

King, G. 2014: "Exaptation and synanthropic insects: a diachronic interplay between Biology and Culture". Environmental Archaeology 19 (1): 12-22. https://doi.org/10.1179/1749631413y.0000000011

King, G.; Kenward, H.; Schmidt, E. y Smith, D. 2014: "Six-legged hitchhikers: an archaeobiogeographical account of the early dispersal of grain beetles". Journal of the North Atlantic 8 (23): 1-18. https://doi.org/10.3721/037.006.m901

Kuijt, I. y Finlayson, B. 2009: "Evidence for food storage and predomestication granaries 11,000 years ago in the Jordan valley". Proceedings of the National Academy of Sciences of the United States of America 106 (27): 10966-10970. https://doi.org/10.1073/pnas.0812764106

Longstaff, B. C. 1981: "Biology of the grain pest species of the genus Sitophilus (Coleoptera: Curculionidae): a critical review”. Protection Ecology 3 (2): 83-130.

Maca-Meyer, N.; Arnay-de-la-Rosa, M.; Rando, J. C.; Flores, C.; González, A.; Cabrera, V. y Larruga, J. M. 2004: "Ancient mtDNA analysis and the origin of the Guanches". European Journal of Human Genetics 12: 155-162. https://doi.org/10.1038/sj.ejhg.5201075

Marcy, G. 1940: "La vraie destination des Pintaderas des îles Canaries". Journal de la Société des Africanistes X: 163-180. https://doi.org/10.3406/jafr.1940.2491

Mediouni Ben Jemâa, Jouda, Nesrine Tersim, Karima Taleb Toudert, and Mohamed Larbi Khouja. 2012: "Insecticidal Activities of Essential Oils from Leaves of Laurus Nobilis L. from Tunisia, Algeria and Morocco, and Comparative Chemical Composition." Journal of Stored Products Research 48: 97-104. https://doi.org/10.1016/j.jspr.2011.10.003

Meurers-Balke, J. y Lüning, J. 1992: "Some aspects and experiments concerning the processing of glume wheats". En P. C. Anderson (ed.): Préhistoire de l'agriculture: nouvelles approches expérimentales et ethnographique. Monographie du CRA 6, CNRS. Paris: 341-362

Morales, J. 2010: El uso de las plantas en la Prehistoria de Gran Canaria: alimentación, agricultura y ecología. Ed. Cabildo de Gran Canaria. Gáldar, Gran Canaria. 
Morales, J.; Henríquez-Valido, P.; Moreno-Benítez, M.; Naranjo-Mayor, Y. y Rodríguez-Rodríguez, A. 2018: "Long-Term Food Storage, Insects, Pests and Insecticides: Archaeological Evidence from Pre-Hispanic (ca. 500-1500 AD) Granaries in Gran Canaria (Canary Islands, Spain)". Techniques \& Culture, Le temps des aliments 69: 126-129.

Morales, J.; Rodríguez-Rodríguez, A.; González-Marrero, M. C.; MartínRodríguez, E.; Henríquez-Valido, P. y Del-Pino-Curbelo, M. del 2014: "The archaeobotany of long-term crop storage in Northwest African communal granaries: a case study from Pre-Hispanic Gran Canaria (Cal. Ad 1000-1500)". Vegetation History and Archaeobotany 23 (6): 789-804. https://doi.org/10.1007/s00334-014-0444-4

Morales, J.; Rodríguez-Rodríguez, A. y Henríquez-Valido, P. 2017: "Agricultura y recolección vegetal en la arqueología prehispánica de las Islas Canarias (siglos III-XV d.C.): la contribución de los estudios carpológicos". En: J. Fernández Eraso et al.: Miscelánea en Homenaje a Lydia Zapata (1965-2015). Bilbao: Universidad del País Vasco/Euskal Herriko Univertsitatea, Argitalpen Zerbitzua Servicio Editorial: 189-219.

Morales Matos, G. 2001: "Las Islas Canarias ¿una región aislada?”. Boletín de la Asociación de Geógrafos Españoles 32: 155-175.

Morales Padrón, F. 2008: Canarias: crónicas de su conquista. Ed. Cabildo de Gran Canaria. Las Palmas de Gran Canaria.

Moreno, M. A. y González, P. 2013: "Una perspectiva territorial al uso del suelo en la Gran Canaria prehispánica (siglos XI-XV)". Tabona: Revista de Prehistoria y de Arqueología 20: 9-32.

Moret, P. 1996: "Boletín de la SEA". Boletín de la Sociedad Entomológica Aragonesa 16: 183-188.

Naranjo-Mayor, Y. y Rodríguez-Rodríguez, A. 2015: “Artefactos e instrumentos de piedra en un espacio de almacenamiento colectivo. El caso de El Cenobio de Valerón (Gran Canaria, España)". Munibe Antropologia-Arkeologia 66: 291-308. https://doi.org/10.21630/maa.2015.66.16

Navarro Mederos, J. F. 1997: “Arqueología de Las Islas Canarias”. Espacio, Tiempo y Forma, serie I Prehistoria y Arqueología 10: 447-478.

Onrubia Pintado, J. 1986. "Sellos y marcas de propiedad de graneros fortificados del Aurès (Argelia). Consideraciones etnoarqueológicas en torno a las presuntas correlaciones norteafricanas de las pintaderas de Gran Canaria". Trabajos de Prehistoria 43 (1): 281-308.

Onrubia Pintado, J. 2003: La Isla de Los Guanartemes : territorio, sociedad y poder en la Gran Canaria indigena (siglos XIV-XV). Cabildo Insular de Gran Canaria.

Panagiotakopulu, E.; Buckland, P. C.; Day, P. M. y Doumas, C. 1995: "Natural insecticides and insect repellents in antiquity: a review of the evidence". Journal of Archaeological Science 22 (5): 705-710. https://doi.org/10.1016/s0305-4403(95)80156-1

Panagiotakopulu, E. 2001: "New records for ancient pests: archaeoentomology in Egypt". Journal of Archaeological Science 28: 1235-1246. https://doi.org/10.1006/jasc.2001.0697

Panagiotakopulu, E.; Buckland, P. C. y Kemp, B. J. 2010: "Underneath ranefer's floors - urban environments on the desert edge". Journal of Archaeological Science 37 (3): 474-481. https://doi.org/10.1016/j.jas.2009.09.048

Panagiotakopulu, E.; Higham, T.; Sarpaki, A.; Buckland, P. y Doumas. C. 2013: "Ancient pests: the season of the Santorini Minoan volcanic eruption and a date from insect chitin". Naturwissenschaften 100 (7): 683-689. https://doi.org/10.1007/s00114-013-1068-8

Peña-Chocarro, L.; Pérez-Jordà, G.; Morales, J. y Zapata, L. 2015: "Storage in traditional farming communities of the Western Mediterranean: ethnographic, historical and archaeological data". Environmental Archaeology 20 (4): 1-11. https://doi.org/10.1179/1749631415y.0000000004

Plarre, R. 2010: "An attempt to reconstruct the natural and cultural history of the granary weevil, Sitophilus granarius (Coleoptera: Curculionidae)". European Journal of Entomology 107 (1): 1-11. https://doi.org/10.14411/eje.2010.001

Reimer, P. J.; Bard, E.; Bayliss, A.; Beck, J. W.; Blackwell, P. G.; Bronk Ramsey, C.... y Van Der Plicht, J. 2013: "IntCal13 and Marine13 Radiocarbon Age Calibration Curves 0-50,000 Years cal BP". Radiocarbon 55 (4): 1869-1887. https://doi.org/10.2458/azu_js_rc.55.16947

Rodilla J. M.; Tinoco M. T.; Morais J. C.; Giménez, C.; Cabrera, R.; Martín-Benito, D.... y González-Coloma, A. 2008: "Laurus novocanarien- sis essential oil: seasonal variation and valorization". Biochemical System Ecology 36: 167-176. https://doi.org/10.1016/j.bse.2007.09.001

Rodríguez Rodríguez, A.; Morales, J.; Pino Curbelo, M. del; Naranjo Mayor, Y.; Martín Rodríguez, E. y González Marrero, M. C. 20112012: "Espacios de producción especializada, excedentes y estratificación social en la Gran Canaria pre-europea". Tabona: Revista de Prehistoria y de Arqueología 19: 101-123.

Rodríguez-Varela, R.; Günther, T.; Krzewinska, M.; Storå, J.; Gillingwater, T. H.; MacCallum, M.... y Girdland-Flink, L. 2017: “Genomic analyses of pre-european conquest human remains from the Canary Islands reveal close affinity to modern North". Current Biology 27: 3396-3402. https://doi.org/10.1016/j.cub.2018.04.083

Salido Domínguez, J. 2015: "Los graneros sobreelevados rurales en la Hispania romana: materiales y técnicas constructivas". Arqueología de la Arquitectura 12: 1-16. https://doi.org/10.3989/arq.arqt.2015.008

Santana Cabrera, J.; Velasco Vázquez, J. y Rodríguez Rodríguez, A. 2012: "Patrón cotidiano de actividad física y organización social del trabajo en la Gran Canaria prehispánica (siglos XI-XV): la aportación de los marcadores óseos de actividad física". Tabona Revista de Prehistoria y de Arqueología 19: 125-163.

Santana Cabrera, J.; Velasco Vázquez, J. y Rodríguez Rodríguez, A. 2015: "Entheseal changes and sexual division of labor in a northafrican population: the case of the Pre-Hispanic Period of the Gran Canaria Island (11th-15th C. CE)". HOMO - Journal of Comparative Human Biology 66 (2): 118-138. https://doi.org/10.1016/j.jchb.2014.10.005

Schweingruber, F. H. 1990: Anatomie europäischer Hölzer. Paul Haupt. Bern y Stuttgart.

Sigaut, F. 1981: "Identification des techniques de conservation et de stockage des grains”. En M. Gast y F. Sigaut (eds.) Les techniques de conservation des grains à long terme. CNRS. Paris: 156-180.

Sigaut, F. 1988: "A method for identifying grain storage techniques and its application for European agricultural history". Tools and Tillage VI (1): 3-32.

Springer, R. A. 2001: Origen y uso de la escritura libico-bereber en Canarias. Centro de Cultura Popular Canaria. Arafo.

Trematerra, P.; Sciarreta, A. y Tamasi, E. 2000: "Behavioural responses of Oryzaephilus surinamensis, Tribolium castaneum and Tribolium confusum to naturally and artificially damaged durum wheat kernels". Entomologia Experimentalis et Applicata 94 (2): 195-200.

Van der Veen, M. 2007: "Formation processes of desiccated and carbonized plant remains - the identification of routine practice". Journal of Archaeological Science 34 (6): 968-990. https://doi.org/10.1016/j.jas.2006.09.007

Velasco Vázquez, J. 1998: "Economía y dieta de las poblaciones prehistóricas de Gran Canaria: una aproximación bioantropológica”. Complutum 9: 137-160

Velasco Vázquez, J. 2015: “Más allá del horizonte: una 'perspectiva humana' del poblamiento de Canarias". En A. J. Farrujía (ed.): Orígenes. Enfoques interdisciplinares sobre el poblamiento indigena de Canarias. Ediciones Idea. Tenerife.

Winterhalder, B.; Puleston, P. y Ross, C. 2015: "Production risk, interannual food storage by households and population-level consequences". Seasonal Prehistoric Agrarian Societies. Environmental Archaeology 20 (4): 337-348. https://doi.org/10.1179/1749631415y.0000000025

\section{ANEXOS: ARCHIVOS COMPLEMENTARIOS}

En la versión en línea (menú Herramientas del artículo) pueden consultarse dos archivos complementarios en formato Excel:

AC1. Números detallados de los restos de insectos documentados en Risco Pintado.

AC2. Número estimado de los restos de plantas no explotadas por los antiguos canarios recuperadas en Risco Pintado. 